\title{
De la paz imperfecta a la agencia pacifista
}

\author{
From the imperfect peace to the pacifist agency
}

Da paz imperfeita à agência pacifista

Recepción: 30/01/2020

Evaluación: 29/04/2020

Aceptación: 28/05/2020

Artículo de Investigación - Revisión

https://doi.org/10.19053/01227238.11917

Juan Manuel Jiménez Arenas ${ }^{1}$

Universidad de Granada, España

Instituto Universitario de la Paz y los Conflictos

https://orcid.org/0000-0002-4165-0187

\section{RESUMEN}

El objetivo del estudio es contribuir, desde la doble perspectiva de la paz imperfecta y del giro epistemológico, a revisar críticamente el concepto de poder como base para la agencia pacifista. Originalidad: este trabajo se centra, por primera vez, en la agencia como posibilidad para que la paz ocupe cada vez un mayor espacio personal, público y político. Método: es un trabajo de investigación cualitativa que, desde una perspectiva compleja, parte del concepto de paz imperfecta y del giro epistemológico, empleando las estrategias del análisis crítico de textos de investigación para la paz y escritos que versan sobre el concepto de poder, especialmente de Hannah Arendt, Michel Foucault, Michael Mann, Kenneth Boulding y John
Holloway, entre otras/os. Este diálogo nos permite concluir que el poder también puede ser considerado como la capacidad que tenemos todos de actuar de manera coordinada para promover el desarrollo de las capacidades humanas deseables. Entendido de esta forma, el poder genera paz, la cual debe ocupar el mayor espacio personal, público y político. Así las cosas, esta extensión capilar de la paz no debe valorarse solo como una medida del empoderamiento pacifista, sino una consecuencia de la agencia pacifista.

Palabras clave: Investigación para la paz; capacidades humanas; complejidad; transmodernidad; transdisciplinariedad.

1 Doctor por la Universidad de Granada, profesor titular del departamento de Prehistoria y Arqueología y director del Instituto Universitario de la Paz y los Conflictos de dicha universidad. Ha sido coordinador del Programa de Formación de Doctores convenido por la Universidad del Valle, la UGR y la Asociación Universitaria Iberoamericana de Posgrados, correo electrónico: jumajia@ ugr.es 

contribute from the dual perspective of imperfect peace and epistemological turn to review in a critical way the concept of power as the basis for pacifist agency. Originality this work focuses, for the first time, on agency as a possibility for peace to take part in more personal, public and political spaces. Method is a qualitative research work that starts, from a complex perspective, from the concept of imperfect peace and the epistemological turn, using the strategies of critical analysis of research texts for peace and writings that deal with the concept of power, especially of Hannah Arendt, Michael Foucault, Michael Mann, Kenneth Boulding and
John Holloway, among others. Their dialogue allows us to conclude that power can also be considered as the ability that all human beings have to act in a coordinated way in order to promote the development of desirable human skills. Understood in this way, power generates peace, which must occupy the greatest personal, public and political space. Thus, this extension of peace should not be valued only as a measure of pacifist empowerment, but also as a consequence of the peacemaker agency.

Key words: Research for peace; human skills; complexity; trans-modernity; transdisciplinary.

\section{RESUMO}

O objetivo do estudo é contribuir a partir da dupla perspectiva da paz imperfeita e da virada epistemológica para revisar o conceito de poder como base para a agência pacifista. Originalidade: este trabalho está centrado, pela primeira vez, na agência como possibilidade para que a paz ocupe cada vez mais um maior espaço pessoal, público e político. Método: é um trabalho de pesquisa qualitativa que parte, de uma perspectiva completa, do conceito de paz imperfeita e da virada epistemológica, empregando as estratégias da análise crítica de textos de pesquisa para a paz e escritos que tratam do conceito de poder, especialmente de Hannah Arendt, Michael Foucault, Michael Mann, Kenneth Boulding e John
Holloway, entre outras/os. Este diálogo nos permite estabelecer como conclusão que, o poder também pode ser considerado como a capacidade que temos, todos os seres humanos, para atuar de maneira coordenada para promover o desenvolvimento das capacidades humanas desejáveis. Entendido desta forma, o poder gera paz, a qual deve ocupar o maior espaço pessoal, público e político. Desta forma, esta extensão capilar da paz não deve valorizar-se somente como uma medida do empoderamento pacifista, mas como uma consequência da agência pacifista.

Palavras-chave: Pesquisa para a paz; Capacidades humanas; Complexidade; Transmodernidade; Transdisciplinaridade. 


\section{INTRODUCCIÓN}

El presente artículo es fruto de una reflexión de décadas de investigación para la paz. A las puertas del vigésimo aniversario de la publicación de obras capitales para entender la investigación para la paz en lengua castellana Filosofía para hacer las paces de Vicent Martínez Guzmán y La paz imperfecta de Francisco A. Muñoz Muñoz- es oportuno seguir avanzado en su desarrollo, siempre sobre los pilares que el filósofo castellonense y el historiador granadino nos han legado.

La validez de los textos académicos no debe medirse por el número de citas sino por su fertilidad. Esto es, por su capacidad para generar debate y desarrollarse. Por tanto, las obras no son textos acabados, y en ese sentido son imperfectos, están en permanente construcción en medio del diálogo necesario entre las/os autoras/es y las/os lectoras/es que recurren a ellos. $Y$ en ese sentido, coinciden con la paz.

Transitaré, de forma crítica, por algunos de los principales conceptos de la investigación para la paz, y lo haré bajo el paraguas del giro ontológico y del giro epistemológico ${ }^{2}$. El primero, nos revela a un ser humano humanizado, paradójico, capaz, despojado de esencias: el ser humano, conflictivo, no es ni violento ni pacífico por naturaleza, posee capacidades para la gestión pacífica y violenta de los conflictos ${ }^{3}$. Por tanto, las esencias dejan paso a las características. Los seres humanos hemos sido, y somos, históricos, contingentes y mutables. Respecto a la segunda, si lo que nos preocupa es la paz, investiguemos la paz, convirtámosla en una categoría de análisis y abordémosla desde una perspectiva transdisciplinar.

Este trabajo no resulta de una investigación en el sentido más estricto de la palabra. Más bien de la evolución de un concepto procesual e inacabado: la paz imperfecta. De la profundización en el vínculo entre la teoría y la práctica que debe conllevar cualquier investigación vinculada a la paz. Para ello, he estructurado el presente artículo en cinco bloques que dialogan entre sí y que se desarrollan según el siguiente esquema: comienzo preguntándome si es posible investigar la paz para concluir que sí; continúo reflexionando sobre complejidad, transmodernidad y transdisciplinariedad como bases para enraizar la investigación para la paz; a continuación, abordo la cuestión de los modelos ontológicos que tanta influencia tienen en la forma que tenemos de ejercer nuestros respectivos trabajos; posteriormente planteo el carácter imperfecto de la paz como aproximación a la investigación-práctica para la paz; después, sugiero una reflexión sobre el concepto de poder y para ello me apoyo en autores/as que han sido claves para entender esta noción primordial para todas las disciplinas humanas;

2 Vicent Martínez Guzmán, Filosofía para hacer las paces (Barcelona: Icaria, 2001).

3 Francisco A. Muñoz, "La paz imperfecta ante un universo en conflicto", en La paz imperfecta, ed. Francisco A. Muñoz (Granada: Editorial de la Universidad de Granada, 2001). 
para finalizar, me detengo en cómo el poder y la paz se entreveran en el empoderamiento y la agencia pacifistas, lo que permite vincular la teoría con la práctica.

\section{1. ¿Es posible investigar la paz?}

En principio, parece una pregunta demasiado simple. No obstante, tiene su sentido. Por una parte, es frecuente que la investigación para la paz se centre en el análisis de la violencia. Por otra, es relativamente fácil visibilizar los aspectos prácticos, normativos y axiológicos con los que se vincula; caracterizarla como un noble ideal, para muchas/os imposible de conseguir. Incluso tratarla como objeto de investigación. Pero, ¿puede ser considerada una categoría de análisis? Respecto a este interrogante, sostengo que sí.

La paz como categoría de análisis, permite reconocer los complejos procesos sociales mediante los cuales explicar cómo se estructuran y expresan aquellos comportamientos, acciones, pensares, sentires que han permitido y permiten el desarrollo de las capacidades humanas deseables; cómo, en tanto construcciones humanas históricas, contingentes y, por tanto, mutables, los comportamientos pacíficos no son exclusivamente dependientes, y por tanto opuestos, a la violencia ${ }^{4}$. De esta forma, al igual que ocurre con el género - por ejemplo-, la consideración de la paz como categoría de análisis permite desarrollos teóricos, re-crear conceptos, desplegar metodologías que permiten reconocerla, visualizarla, en todo tiempo y espacio y por parte de todos los agentes (entidades humanas). Esta última parte se puede resumir en que la investigación para la paz tiene potencial para las transformaciones epistemológica y ontológica. Por esta razón, la pregunta es aún procedente puesto que la gran mayoría de las/os investigadoras/es para la paz se han afanado en buscar, y encontrar, de manera brillante en muchas ocasiones, las violencias, para de ese modo establecer certeros diagnósticos sobres sus causas y desarrollos.

La violencia ha sido y sigue siendo la estrella de la investigación para la paz. Por deformación profesional, me centraré en la Historia, de la cual se ha dicho que posee un carácter pedagógico. Es fundamental aprender de los errores del pasado para que no se repitan en el futuro (el énfasis es mío) ${ }^{5}$. La violencia sería considerada en este contexto, el error, lo anómalo. Pero la cuestión de base es: ¿se aprende de los errores? En la cultura popular la respuesta afirmativa está tremendamente arraigada. No obstante, existen numerosos estudios que plantean que los éxitos son lo base del aprendizaje ${ }^{6}$. También sobre que no se aprende de los errores en sí mismos, sino de la capacidad de generar respuestas diferentes a las que inducen

$4 \quad$ Ibíd.

5 "El análisis atento y las consideraciones de fondo de los diversos factores que convergen en un hecho son los que llevan a descubrir la verdad y a prevenir las equivocaciones". [Ibn Jaldun, Introducción a la Historia (Sevilla: Editoriales Unidas Andaluzas, 1985), 33].

6 Dos ejemplos los tenemos en los artículos firmados por Histed y colaboradas/es y por Zioga y colegas: Mark H. Histed, Anitha Pasupathy y Earl K. Miller, "Learning Substrates in the Primate Prefrontal Cortex and Striatum: Sustained Activity Related to Successful Actions", Neuron vol. 63, n. 2 (2009); Ioanna Zioga, Rawan Hassan y Caroline Di Bernardi Luft, "Success, but not failure feedback guides learning during neurofeedback: An ERP study", NeuroImage vol. 200, n. ${ }^{\circ} 1$ (2019). 
al error ${ }^{7}$. El giro epistemológico se sustenta también desde las neurociencias. Por tanto, si lo que nos preocupa es la violencia y pretendemos la paz, dejemos de ocuparnos de la violencia y centrémonos en la paz. Esto no significa en modo alguno olvidar la violencia, no somos (no soy) tan ingenuo. Si no existiese la violencia, la cual, dicho sea de paso, por muy escasa que sea resulta demasiada, no estaríamos afanados en transformar la realidad en pos de mundos más pacíficos. Y para ello, desde la perspectiva de la paz imperfecta, proponemos un giro ontológico (también antropológico y epistemológico) que sitúe la paz en el centro de nuestras ocupaciones como profesionales de la docencia y la investigación.

Para ello partiremos de dos series de premisas:

- La consideración de la paz como un objeto de estudio complejo ${ }^{8}$;

- La necesidad de su caracterización como un campo transdisciplinar como abordaje que contribuya a desentrañar su complejidad.

Para contribuir a tal fin, se propone una matriz unitaria y comprensiva que, a partir de cinco ejes, interaccionados entre sí, nos permita orientar nuestra labor como investigadores ${ }^{9}$.

Una consideración positiva, abierta, sutil y dialógica de los conflictos. Con el paso del tiempo las/os investigadoras/es hemos comprendido que los conflictos no eran siempre la antesala de la violencia, sino el resultado de las diferencias en las percepciones, objetivos y desarrollo de capacidades entre diferentes entidades humanas. El conflicto es fuente de creatividad y de oportunidades, y abre la posibilidad al cambio y a la transformación.

Debemos aceptar el conflicto como primera condición de nuestra libertad y reconocemos que, desde los inicios de nuestra Historia, la mayor parte de aquéllos se han gestionado pacíficamente. La cultura es, desde el principio, un instrumento que intenta definir los vínculos, mediar, establecer relaciones con la naturaleza y, sobre todo, con nosotros mismos. Por ello, el conflicto forma parte del proceso de interacción social en el que los intereses de los individuos y grupos se entrelazan, se regulan, transforman o resuelven en ocasiones, convirtiéndose en una parte esencial del complejo desarrollo de socialización que experimenta toda entidad humana. Entender el conflicto desde esta perspectiva supone formas de reconocimiento mutuo (asimilar la otredad y la variedad humana) y de comprensión de las percepciones del otro (la inexistencia de una única verdad, de una única visión de la realidad, etc.).

1. La paz imperfecta y sistémica. La paz imperfecta, la inacabada, en permanente construcción, responsabilidad de todas y todos, procesual; paradójica, porque convive con la violencia. Y este es uno de los aspectos que más gustaría subrayar. Para que haya paz no es necesario que desparezca

$7 \quad$ Caroline Di Bernardi Luft, Guido Nolte y Joydeep Bhattacharya, "High-Learners Present Larger Mid-Frontal Theta Power and Connectivity in Response to Incorrect Performance Feedback”, Journal of Neuroscience vol. 33, n. 5 (2013).

8 Isabel Hernández Arteaga, José Alberto Luna Hernández, Martha Cecilia Cadena Chala, "Cultura de Paz: Una construcción educativa aporte teórico", Revista Historia de La Educación Latinoamericana, vol. 19, n. 28 (2017).

9 Véanse, por ejemplo: Muñoz, "La paz imperfecta”; Francisco A. Muñoz y Beatriz Molina Rueda, "Una Cultura de Paz compleja y conflictiva. La búsqueda de equilibrios dinámicos", Revista Paz y Conflictos n. ${ }^{\circ} 3$ (2010). 
la violencia. Ambas conviven. Una paz que no brota como respuesta a la violencia, sino que emana autónoma, plena, como el desarrollo de las capacidades deseables de los seres humanos. Es una respuesta optimizada a la complejidad de los seres humanos fruto de la inmensa cantidad y calidad de conflictos con los que convivimos.

2. La crítica a la violencia ${ }^{10}$. Que el giro nos permita situar la paz en el centro de nuestras preocupaciones, prácticas e investigativas, no significa que se olvide la violencia. Existen la desigualdad, la injusticia, las muertes, el hambre, etc. No obstante, la violencia comparte con la paz ese carácter imperfecto puesto que nunca ocupa todo el espacio de las relaciones entre entidades humanas.

3. La mediación es un concepto que permite relacionar elementos distintos a través de agentes que cumplen la función de interponerse entre varias circunstancias. Considerándola desde una perspectiva filosófica-epistémica, la mediación es una reflexión racional en la que se incorporan más ideas y un proceso dialógico a través del cual se pueden encontrar las relaciones. Creo que es importante abordarla tanto en su aspecto más abstracto, en la articulación de las ideas, como en su concreción práctica, en la interpretación de las realidades y las acciones prácticas. Por ello la mediación tiene una dimensión topológica, de escenario, de lugar, y otra dialógica, como recurso epistémico que puede ser reconocido en determinadas relaciones y acciones.

4. El empoderamiento y la agencia pacifistas que parten de una concepción pacifista y pacífica del poder. Entendido como la capacidad que tienen, tenemos, todas las entidades humanas para transformar la realidad mediante el concurso de la paz y conciencia de la misma, respectivamente. El poder deja de ser ese elemento exógeno, distante, exclusivamente coercitivo, limitante hasta la alienación. El poder también tiene un carácter reticular y capilar, lo que le permite alcanzar todos los espacios y ser ejercido por todas las entidades humanas. El poder es red, colaboración, cooperación, compartición. El poder no se conquista, se ejerce.

A partir de aquí, planteo tres enunciados (hipótesis) que están íntimamente unidos a la paz imperfecta:

- $\mathrm{H}_{1}$ : La paz y la violencia son construcciones culturales, históricas, contingentes y mutables.

- $\mathrm{H}_{2}$ : La inmensa mayoría de los conflictos se han gestionado, a lo largo de la Historia, también en el presente, de manera pacífica.

- $\mathrm{H}_{3}$ : Todas las entidades humanas tienen poder y lo ejercen.

10 Originalmente, Francisco A. Muñoz propuso "deconstrucción de la violencia”. Ahora bien, desde mi perspectiva, el uso de dicha expresión remite a un método concreto de aproximación a los textos popularizada por Jacques Derrida que no es el aplicado a la matriz unitaria y comprensiva. 


\section{Complejidad, transmodernidad y transdisciplinariedad}

Obviamente, por razones de formato y de entidad de cada una de estas tres moles epistemológicas, no puedo entrar a discutir cada una con el detalle que merecerían. No obstante, compartiré unas pinceladas que ilustran y se avienen con la propuesta de investigación para la paz propuesta en este artículo.

\section{Enfocando la investigación para la paz desde la complejidad}

La complejidad no puede considerarse una teoría; más bien, como propone Jorge Wagensberg, un conjunto de "ideas acerca de..." ${ }^{11}$ y se refiere a la convivencia de hechos, acciones, determinaciones, indeterminaciones, certidumbres, incertidumbres, azares, caos, contextos, en los que se producen y desarrollan los fenómenos que podemos percibir ${ }^{12}$. Dicho de otra manera, la complejidad atiende a las interrelaciones que se producen entre los elementos constitutivos de un sistema de las que surgen características emergentes diferentes a las de las variables originales. También se pueden añadir los tránsitos entre estados de orden y desorden, con especial interés en el desorden, porque la vida tiende a é$^{13}$. Seamos conscientes de que el máximo orden es la muerte. Por tanto, si la paz es vida, la paz implica desorden. Este aspecto resulta especialmente atractivo si vinculamos paz a capacidad para transformar (esto es, poder como veremos más adelante). La investigación para la paz debe convertir a las entidades humanas en agentes críticos que cuestionen aquellos aspectos del statu quo que no promueve, e incluso impide el desarrollo de las capacidades humanas deseables ${ }^{14}$. La paz no es inacción, no resulta de un estado de armonía, de quietud, que la relacionaría con la perfección. Un mundo imperfecto, en continua transformación, demanda de una paz que disfrute de esa misma condición.

El azar, del que he hablado anteriormente, implica la susceptibilidad a las condiciones iniciales ${ }^{15}$. Por tanto, un pequeño cambio en las mismas puede dar lugar a grandes transformaciones. Esta característica deviene coherente con el carácter hologramático de la realidad: el todo incluido en la parte que conforma al todo ${ }^{16}$. El carácter rizomático de la realidad ${ }^{17}$. Esto es clave para entender el meollo de la paz imperfecta: no es necesario cambiarlo todo, porque cambiando algo ya estamos incidiendo, transformando el todo. La paz no es solo paz cuando proveniente de las instituciones e incide en las denominadas "estructuras".

\footnotetext{
11 Jorge Wagensberg, Ideas acerca de la complejidad del mundo (Barcelona, Tusquets, 1985).

12 Edgar Morin, Introducción al pensamiento complejo (Barcelona, Gedisa, 1998), 59-50.

13 Carlos E. Maldonado, Significado e impacto social de las ciencias de la complejidad (Bogotá: Ediciones desde abajo, 2013).

14 Jesús Sánchez Cazorla, "Ciencia y tecnología para la paz", en Ciencia, tecnología y sociedad. Contribuciones para una cultura de la paz, eds. F. Javier Rodríguez Alcázar, Rosa M. Medina Doménech y Jesús A. Sánchez Cazorla (Granada: Editorial de la Universidad de Granada, 1997), 15.

15 David Ruelle, Azar y Caos (Madrid: Alianza, 1993), 52.

16 Morin, Introducción, 107 y ss.

17 Gilles Deleuze y Félix Guattari, Mil mesetas. Capitalismo y esquizofrenia (Valencia: Pre-Textos, 2008).
} 
También cuando se desarrolla en lo cotidiano y por parte de todas las entidades humanas. Ocurre que existe un sesgo a la hora de visibilizar paz y violencia. La primera resulta casi invisible, la segunda omnipresente. Por ello es fundamental mostrar todos los espacios, tiempos y agentes de construcción de paz. En mi caso, como especialista en la interpretación del pasado, acentúo su relevancia a lo largo de la Historia ${ }^{18}$. No obstante, determinadas frases que se han convertido en íconos de las culturas popular y académica, provocan la interpretación de nuestro pasado en un sentido diferente. Entre ellas destacaré: "Si vis pacem para bellum" (atribuida a Julio César, aunque basada en una afirmación de Vegecio), "La paz, partera de la historia" (Karl Marx) y "la lucha por la supervivencia" (Charles Darwin).

Por otra parte, y es también otro de los aspectos centrales de la paz imperfecta, la complejidad nos sitúa ante la convivencia de aspectos aparentemente antagónicos. Evita dos características muy de la Modernidad: la dualización y la jeraquización y tiende a lo dialógico como alternativa a interpretaciones simplistas, mecanicistas, lineales, teleológicas y dogmáticas. Es fundamental pensar que para que un contexto sea considerado pacífico, no debe desaparecer toda la violencia. La paz y la violencia coexisten. Y el contexto colombiano da buena cuenta de ello.

Tabla 1. Síntesis de las diferencias entre los enfoques multi-, inter- y trans-.

\begin{tabular}{|l|l|}
\hline Multi- & Análisis individuales, yuxtaposición, asociación \\
\hline Inter- & Análisis paralelos, márgenes de las disciplinas, relación \\
\hline Trans- & $\begin{array}{l}\text { Análisis conjuntos, asunciones básicas, asimilación de los conoci- } \\
\text { mientos, integración }\end{array}$ \\
\hline
\end{tabular}

La complejidad permite, además y a partir de los enfoques multi-, inter- y trans- (tabla 1), sobre todo este último, visualizar y ser consciente de los cambios que se están produciendo en un mundo cada vez más conectado y en el que la hibridación entre humanos y máquinas - lo que Donna Haraway denominó

18 Véanse, por ejemplo: Francisco A. Muñoz Muñoz y Beatriz Molina Rueda, Beatriz (eds.), Cosmovisiones de Paz en el Mediterráneo antiguo y medieval (Granada: Editorial de la Universidad de Granada, 1998); Francisco A. Muñoz Muñoz y Mario López Martínez (eds.), Historia de la paz: tiempos, espacios y actores (Granada: Editorial de la Universidad de Granada, 2000); Francisco A. Muñoz Muñoz (ed.), La paz imperfecta (Granada: Editorial de la Universidad de Granada, 2001); Francisco A. Muñoz Muñoz y Carmelo Pérez Beltrán (eds.), Experiencias de Paz en el Mediterráneo (Granada: Editorial de la Universidad de Granada, 2003); Jorge Bolaños Carmona y Francisco A. Muñoz (eds.), Los habitus de la paz. Teorías y prácticas de la paz imperfecta (Granada: Editorial de la Universidad de Granada, 2011); Juan M. Jiménez Arenas, “Pax Homínida. Una aproximación imperfecta a la evolución humana”, en Los habitus de la paz. Teorías y prácticas de la paz imperfecta, eds. Jorge Bolaños Carmona y Francisco A. Muñoz (Granada: Editorial de la Universidad de Granada, 2011); Juan M. Jiménez Arenas y Francisco A. Muñoz Muñoz (eds.), La Paz, partera de la historia (Granada: Editorial de la Universidad de Granada, 2013); Francisco Alfaro Pareja, "Capacidades para la paz en las negociaciones para el reconocimiento de la Independencia de Venezuela por parte de España (1833 y 1846)”, Revista de Paz y Conflictos, vol. 7 (2014); Juan M. Jiménez Arenas, “Complexity, Cooperation and Childhood: An Evolutionary Perspective", en Children, Spaces and Identity, eds. Margarita Sánchez Romero, Eva Alarcón García y Gonzalo Aranda Jiménez (Oxford: Oxbow Books, 2015); Francisco Alfaro Pareja, La historia oculta de la Independencia de Venezuela: De la guerra idealizada a la paz imperfecta (Caracas: Editorial Alfa, 2016); Francisco A. Muñoz Muñoz y Juan M. Jiménez Arenas, "Histoire et recherche pour la paix. Expériences autour de la Méditerranée", Cahiers de la Méditerranée, n. 91 (2015); Juan M. Jiménez Arenas, "Evolución humana y paz. Una aproximación desde la teoría y la práctica", Vínculos de Historia, n. ${ }^{\circ} 7$ (2018). 
cyborgs ${ }^{19}$ - está condicionando las relaciones sociales, cambiantes a una velocidad desconocida hasta las últimas décadas. La adopción de enfoques complejos nos permite dar respuestas diferentes, posiblemente más adecuadas a un mundo en continua transformación. Ahora bien, para un mejor análisis y diagnóstico de los distintos contextos es importante, como desarrollaré a continuación, emprender abordajes transdisciplinares a partir de los que evitar las oposiciones disciplinares y en los que las continuas comunicaciones y convivencia se conviertan en una necesidad epistemológica. A partir de aquí, la propuesta es generar una investigación más respetuosa con los diferentes aspectos del conocimiento en las que el diálogo forme parte fundamental del método.

\section{De los pos- a lo trans- y su influencia en la investigación para la paz}

En primer lugar, tal y como se ha comentado anteriormente, la transdisciplinariedad es un intento de presentar una alternativa a los enfoques investigativos fragmentados propios de la Modernidad que trata de orillar más allá de los postulados de la Posmodernidad. En segundo término, consideraré la transdisciplinariedad como aspecto consustancial del conocimiento que nos sitúa entre la duda y la humildad, y que pretende contribuir a la superación del egocentrismo disciplinar. En mi forma de entender la transdisciplinariedad, debemos escapar de tres consideraciones: la primera, considerarla únicamente como una reacción contra la hiperespecialización ${ }^{20}$; la segunda, tratarla como una negación de los aportes que cada una de las disciplinas pueda realizar, como una amenaza al estatus de cada una de ellas o como un rechazo a las perspectivas particulares; y la tercera, resaltar que no se trata de enfoques vagos, sino de profundizar en temas comunes, complejos y que requieren de respuestas (desde la teoría a las interpretaciones) conjuntas para las cuales resultan mucho más eficientes y eficaces las estrategias colaborativas. Para ello es capital tener una visión dinámica del conocimiento con estructuras cada vez más abiertas a la colaboración en red. Dicho de otra manera, el marco de la complejidad requiere del recurso a la transdisciplinariedad para la configuración de modelos cosmopolitas que nos permitan plantear formas diferentes de interpretación de la realidad, que nos faciliten alternativas a modelos más propios de la Modernidad ${ }^{21}$.

Ahora bien, tampoco la Posmodernidad ha conseguido, a mi juicio, presentar soluciones creativas y lo suficientemente versátiles al mundo cambiante del que nos ha tocado participar. En buena medida, esta idea se acrecienta, a mi entender, porque la Posmodernidad se gesta como una oposición radical, cuando no extrema, que, en su rechazo de lo moderno, practica de lo que tanto critica, convirtiendo determinadas ideas, instituciones, personas, etc., en asertos

19 Donna J. Haraway, Simians, Cyborgs, and Women. The Reinvention of Nature (New York: Routledge, Taylor and Francis, 1991).

20 UNESCO, Conferencia Mundial sobre la Educación Superior. La educación superior en el siglo XXI. Visión y Acción (1998) http:// unesdoc.unesco.org/images/0011/001136/113602So.pdf (13/05/2014), 13.

21 Gerard Delanty, “The cosmopolitan imagination: critical cosmopolitanism and social theory”, The British Journal of Sociology, vol. 57, n. ${ }^{\circ} 1(2006)$. 
que corren el mismo riesgo que los metarrelatos: ser "totalizadores" y convertirse en dei ex machina que permiten interpretar la realidad en su conjunto. Para cierta parte - muy influyente - de la Posmodernidad, urgía una ruptura, un olvido de las viejas ideas que conducían a la alienación de los seres humanos ${ }^{22}$ que en realidad ni es posible - al menos al nivel planteado- ni, en mi opinión, deseable. Así, para la Posmodernidad, el conocimiento integrado emerge como una ilusión, como una peligrosa idea de la Modernidad. Desde la Transmodernidad no se apuesta por la recuperación de los metarrelatos, sino de dotarnos de la suficiente flexibilidad y capacidad de transformación teórico-metodológica como para ir dando respuestas satisfactorias a un mundo en constante cambio.

La Transmodernidad surge, pues, de la conciencia de cambio, la Posmodernidad de las ausencias. De ahí la necesidad de plantear alternativas que tengan en cuenta aspectos que se pueden considerar positivos de la Modernidad y de la Posmodernidad. La Transmodernidad surge como proyectos de "sistematización" de las relaciones entre las tramas y las urdimbres.

Desde la propuesta de Transmodernidad, que defiendo, no se puede establecer una prevalencia de unos niveles sobre otros. Dicho de otro modo, todos los aspectos son relevantes en la configuración de las realidades. Los factores biológicos, los materiales, los sociales, los culturales, los prejuicios, los discursos..., todos se interaccionan de forma que, además, hacen surgir propiedades emergentes y diferentes a las propias de los elementos originales propias de los sistemas complejos. En este sentido comparto las ideas de Deleuze y Guattari cuando proponen que el pensamiento y, por ende, la epistemología, deben considerarse rizomáticos, sin jerarquías ni subordinaciones ${ }^{23}$. Rizoma y holograma se erigen fundamentales para la sustentación de la paz imperfecta. Y también del poder.

Un ejemplo de lo expuesto lo ejemplifica Elizabeth Grosz, quien, en su libro Time Travels, ha revelado como, en aras del giro narrativo, se han marginado los aspectos biológicos en las caracterizaciones de los complejos sexo-género ${ }^{24}$. Estos olvidos devienen, en mi opinión, en interpretaciones que tienden a ser también reduccionistas; tanto como lo son las posturas biologicistas. Por ende, entraríamos a comprender la ciencia con base en "procesos complejos" y, por lo tanto, desde lo político hablaríamos de constante movimiento, permanente trans-formación, desordenada y vital.

La Transmodernidad alude a un mundo en constante transformación ${ }^{25}$, (imperfecto) y debe apoyarse en la transdisciplinariedad. Por otra parte, la Transmodernidad asume los desafíos de la Modernidad y reconoce los aportes positivos de la misma, aunque responden desde otro lugar ${ }^{26}$. Igualmente, consi-

22 Gianni Vattimo, El fin de la modernidad. Nihilismo y hermenéutica en la cultura posmoderna (Barcelona: Gedisa, 1998).

23 Deleuze y Guattari, Mil mesetas, 12.

24 Elizabeth Grosz, Time Travels. Feminism, Nature, Power (Sydney: Allen \& Unwin, 2004).

25 Rosa M. a Rodríguez Magda, “Transmodernidad: un nuevo paradigma”, Transmodernity: Journal of Peripheral Cultural Production of the Luso-Hispanic World, vol. 1, n. ${ }^{\circ} 1$ (2011): 6.

26 Enrique Dussel, Transmodernidad e interculturalidad (Interpretación desde la Filosofía de la Liberación) (Ciudad de México, 2005) https://red.pucp.edu.pe/wp-content/uploads/biblioteca/090514.pdf (13/05/14), 17. 
dera fundamental la crítica a los aspectos que se han revelado como negativos, algo a lo que la Posmodernidad ha dedicado buena parte de sus esfuerzos. Pero, en la versión de lo transmoderno que propongo, es importante reconocer las paradojas antedichas: los aspectos considerados positivos en los negativos, y viceversa, porque, como ya he explicado anteriormente, existe un predominio de la convivencia de ambos. La Transmodernidad, por tanto, critica, deconstruye, pero no solo; cuenta también con el ánimo de reconstruir y para hacerlo es fundamental el reconocimiento de aquellos aspectos modernos que han servido para el desarrollo de capacidades humanas. “'Trans' es transformación [más allá del estatismo de las esencias], dinamismo [sustancial], atravesamiento de algo en un medio diferente" 27.

Para ello es fundamental establecer diálogos entrecruzados e igualitarios en los que las epistemologías tiendan a la apertura (coexistencia de tendencias heterogéneas). "Su clave no es el post, la ruptura, sino la transubstanciación vasocomunicada de los paradigmas" ${ }^{\prime 2}$. Pienso que este planteamiento dialógico es complementario a la dialéctica y presenta algunas características que son importantes desde la perspectiva de la investigación para la paz: la dialógica no es teleológica, no necesita llegar a fin alguno, no se trata de la superación de los opuestos, sino de la integración, de la creación de interrelaciones que permitan novedades teórico-metodológicas; la dialógica apuesta por la desfragmentación del ser humano y por abordar las problemáticas de investigación contemplando, desde aproximaciones transdisciplinares, al mismo tiempo el máximo de dimensiones y facetas; la dialógica se decanta por lógicas de interrelación, en contraposición a las lógicas de confrontación más vinculadas a la dialéctica; transformación estructuralista para la dialéctica frente a la posibilidad de pequeños cambios (susceptibilidad a las condiciones iniciales) de la dialógica. La dialéctica, en la tradición positivista, "acaba reificando la realidad y encerrándola en conceptos no relacionales, sin percibir en consecuencia su auténtica complejidad"29. Igualmente, es importante que los diálogos se extiendan a los diferentes niveles. Así, por ejemplo, los modelos ontológicos están condicionando la forma que tenemos de aprehender la realidad, pero nuestras prácticas como investigadoras/es también contribuyen a legitimar y justificar determinados modelos ontológicos. Por tanto, sin priorizar, mucho menos sin despreciar, formas diferentes de generar conocimiento, resulta relevante tener en cuenta los modelos ontológicos, antropológicos, epistemológicos, las teorías, las metodologías, las técnicas: desde la toma de datos hasta las interpretaciones y cómo las contamos. La realidad no es solo una cuestión de discursos sobre la misma y por ello defiendo que existe conocimiento de más y de menos calidad y que esta

27 Rosa $\mathrm{M}^{\mathrm{a}}$ Rodríguez Magda, “Transmodernidad: La globalización como totalidad transmoderna”, Revista Observaciones Filosóficas, n. ${ }^{\circ} 4$ (2007), www.observacionesfilosoficas.net/latransmodernidadlaglo.html (13/05/2014).

28 Ibíd.

29 Joaquín Gil Martínez y Ramón A. Feenstra, “La sociedad civil en Gramsci desde una perspectiva antropológica”, en La imagen del ser humano. Historia, literatura y hermenéutica, eds. Javier San Martín y Tomás Domingo Moratalla (Madrid: Biblioteca Nueva, 2011), 34 . 
depende, en buena medida, de los consensos intersubjetivos que seamos capaces de generar.

El pensamiento complejo tiende a la aspiración de un saber no fragmentado, siendo conscientes de lo inacabado e incompleto de cualquier conocimiento generado ${ }^{30}$. No obstante, no olvidamos la necesidad de buenos especialistas que converjan de manera transdisciplinar. El ámbito de la investigación para la paz es un magnífico campo en el que experimentar, en el que continuar tendiendo puentes. De hecho, así ha sido a lo largo de la historia de la disciplina. Los ejemplos de préstamos multidireccionales han sido, y son, abundantes. Y para ello es fundamental la creación de campos transdisciplinares en los que solidaridad, información, comunicación y toma de decisiones por parte de colectivos, de una forma flexible y a la vez robusta ${ }^{31}$, guíen nuestra práctica docente e investigadora. Obviamente, a partir de un enfoque complejo no se puede plantear una oposición entre lo disciplinar y lo transdisciplinar, se trata más bien de fenómenos de convergencia, de creación de redes sin perder la identidad propia de cada disciplina. La diferencia reside en el enriquecimiento y en el aumento de la capacidad que tenemos, desde la asociación, para el planteamiento de problemas de investigación. De hecho, en un reciente artículo publicado en la revista Science, se ha puesto de manifiesto que "The highest-impact science is primarily grounded in exceptionally conventional combinations of prior work yet simultaneously features an intrusion of unusual combinations" ${ }^{\prime 2}$, esto es, un equilibrio entre la tradición disciplinar y la innovación de lo colaborativo, lo reticular. Sin embargo, y a pesar de que cada vez son más las voces que reclaman el carácter transdisciplinar de todas las disciplinas, son escasos los centros que fomentan esta manera de generar conocimientos ${ }^{33}$. Esta tensión entre la especialización disciplinar y la validez y fecundidad de la transdisciplinariedad se ha puesto de manifiesto en una reciente entrevista publicada en el diario El Mundo donde los conversadores, el editor jefe de la revista Nature, Philip Ball (R), y el periodista Miguel G. Corral (P), afirmaron lo siguiente:

P: Muchas grandes ideas de los últimos tiempos provienen de científicos que han sabido ser multidisciplinares y que han tenido una visión amplia de la ciencia...

R: Sí, es cierto. Una de las cosas que nos dice esto es que la división que se hizo de las ciencias en los siglos XVIII y XIX no tiene por qué ser la apropiada hoy en día. Por ejemplo, entender el sistema global del planeta o cómo funciona el clima requiere mucha Química, Física, Biología... [investigación para la paz] $]^{34}$. A medida que necesitamos grandes científicos con una visión amplia de los problemas, el

\footnotetext{
30 Morin, Introducción.

31 Maldonado, Significado e impacto, 44.

32 Brian Uzzi, Satyam Mukherjee, Michael Stringer y Ben Jones, "Atypical Combinations and Scientific Impact", Science vol. 342, n. 6157 (2013): 468 .

33 Marten Scheffer, “The forgotten half of scientific thinking", Proceedings of the National Academy of Sciences, vol. 111, n. ${ }^{\circ} 17$ (2011): 6119.

34 El añadido entre corchetes es mío.
} 
sistema científico va en la dirección opuesta. Los jóvenes científicos tienen demasiada presión para publicar muchos papers y de forma rápida. Eso sólo lo puedes conseguir si estás realmente especializado en un determinado campo. ${ }^{35}$

Se trata, por tanto, de la construcción de racionalidades colectivas que se diferencian en mucho de las ideas originales, de una suma que no se produce a partir de una mera agregación de individualidades sino desde la constitución de un todo autoorganizado que no responde ni a la casualidad ni a la causalidad, que aprende en cuanto genera nueva información (no solo entendida como datos) y que fija su atención en lo relacional.

Así las cosas, y a modo de resumen, la imbricación entre complejidad, Transmodernidad y transdisciplinariedad tiene como objetivos principales superar el egocentrismo disciplinar, evitar la simplicidad en la aprehensión y la interpretación de la realidad, huir del determinismo dando el espacio que merecen el indeterminismo y la incertidumbre, plantear nuestra práctica en términos de lo probable y lo plausible, esquivar también los planteamientos esencialistas, prevenir el dogmatismo y el doctrinarismo y, por último, ser conscientes de nuestros propios prejuicios. Huir de la prevalencia de unos aspectos sobre otros. Sobre todo, tratar de recuperar los aspectos marginados e interconectarlos (de los biológicos a los discursivos) tratando de no hacer prevalecer per se unos sobre otros $^{36}$. Caminando hacia la desfragmentación del ser humano por los caminos de los análisis conjuntos, las asunciones básicas, la asimilación de los conocimientos y la integración.

En definitiva, a partir de la solidaridad - característica íntimamente relacionada con la paz y con los seres humanos - toma de decisiones realizada desde el diálogo profundo entre especialistas de distintas disciplinas como respuesta a las limitaciones que nos impone la complejidad de la realidad que conlleva la incompletitud del conocimiento que seamos capaces de generar. Somos frágiles e interdependientes y una de las estrategias que nos hemos dado los humanos desde los albores de la historia para superarlo ha sido, y es, la cooperación.

Pero la transdisciplinariedad no debe ser una cortina de humo tras la que esconder nuestras vergüenzas, se trata de nuevos retos, nuevos cuestionamientos, nuevas metodologías..., por parte de buenos especialistas cada uno en su materia, los cuales crean redes en las que lejos de perder la identidad disciplinar, esta se afianza porque se enriquece. Por tanto, no es necesario oponer disciplinar a transdisciplinar.

En definitiva, se trata de construir rutas para tratar de evitar los -ismos y, particularmente, los -centrismos. Y para ello es fundamental revisar nuestros modelos ontológicos

35 Miguel G. Corral, La ciencia sigue sufriendo presiones politicas (Madrid: El Mundo, 2014) http://www.elmundo.es/ciencia/2014/05/26/ 537f9b75ca474195148b4575.html (26 de mayo, 2014).

36 De nuevo, el pensamiento rizomático de Deleuze y Guattari, Mil mesetas. 


\section{El sustrato ontológico}

Siguiendo a Edmund Husserl, padre de la fenomenología trascendental, la consideramos la parte de la Filosofía que se reflexiona sobre las esencias formales, esto es, aquellas esencias que convienen a todas las demás esencias ${ }^{37}$. $\mathrm{Ni}$ qué decir tiene el fuerte entronque de la ontología con la identidad ${ }^{38}$ y que el en caso que nos ocupa, los modelos ontológicos remiten a cómo concebimos al ser humano en abstracto. Así las cosas, los caminos de legitimación y justificación de determinados discursos sobre la realidad recurren a las supuestas esencias de los seres humanos.

La influencia de la Ontología en la práctica parece clara. Pero lo es menos la conciencia de cómo nosotras/os participamos en su afianzamiento o debilitamiento mediante nuestra práctica investigadora. Por tanto, ambas se retroalimentan, dando cuenta de otra de las características de la complejidad: la recursividad ${ }^{39}$. Por tanto, nuestra responsabilidad se eleva a la categoría de universalizante.

\section{Sobre la presunta naturaleza humana: ¿Violentos o pacíficos?}

A priori se pueden proponer dos grandes grupos de modelos ontológicos: uno, el negativo del ser humano epitomizado en la frase de Thomas Hobbes, "el ser humano es un lobo para el ser humano", y otro, el positivo, que se compendia en el mito del buen salvaje de Jean-Jacques Rousseau.

Ahora bien, el filósofo inglés nunca escribió la atribuida frase dicha ${ }^{40}$. Aunque de sus palabras sí se deriva que los humanos somos esencialmente violentos. Y si nuestra esencia es violenta, solo puede ser superada mediante el concurso de la cultura. En este caso, en forma de contrato social que deviene de la necesidad de acabar ese estado natural de la humanidad que es la lucha de "todos contra todos" ${ }^{\prime \prime}$.

La propuesta hobbesiana entronca con la tradición judeocristiana: es una extrapolación al ámbito de lo civil de la idea de temor a la autoridad divina. Ya no es dios quien nos infunde el temor sino el soberano. Los súbditos deben sentir miedo a su propia naturaleza humana como forma de legitimación iusnaturalista

37 José Ferrater Mora, “Ontología”, en Diccionario de Filosofía, vol. 3, coord. José Ferrater Mora, nva. ed. por J. M. Terricabras, supervisada por Priscilla Cohn Ferrater Mora (Barcelona: Círculo de Lectores, 2001), 2625.

38 Jiménez Arenas, "Evolución humana y paz", 25-27.

39 Morin, Introducción, 106-107.

40 La frase "El hombre es un lobo para el hombre no un hombre, cuando no se conoce cómo es", se debe a Plauto, quien la incorpora en su obra Asinaria.

41 "Hereby it is manifest that during the time men live without a common power to keep them all in awe, they are in that condition which is called war; and such a war as is of every man against every man. For war consisteth not in battle only, or the act of fighting, but in a tract of time, wherein the will to contend by battle is sufficiently known: and therefore the notion of time is to be considered in the nature of war, as it is in the nature of weather. For as the nature of foul weather lieth not in a shower or two of rain, but in an inclination thereto of many days together: so the nature of war consisteth not in actual fighting, but in the known disposition thereto during all the time there is no assurance to the contrary. All other time is peace." [Thomas Hobbes, Leviathan or The Matter, Forme, \& Power of a Common-wealth Ecclesiasticall and Civil (London: Andrew Crooke, 1651), 76-77. 
del "poder" del soberano. De tal manera que el deber ser (lo axiológico) depende directamente del ser (lo ontológico ${ }^{42}$. El iusnaturalismo ha tenido un tremendo éxito fuera de las ciencias jurídicas como elemento legitimador y justificador de los grandes metarrelatos modernos (liberalismo, marxismo, darwinismo, darwinismo social, sociobiología...), los cuales se han retroalimentado.

En el otro extremo situamos al filósofo ginebrino, los humanos son esencialmente pacíficos. Solo la aparición de la propiedad privada generó egoísmo y, en definitiva, violencia. Rousseau influye en pensadoras/es posteriores (Kropotkin, Ashley Montagu, teóricas feministas, investigadoras/es para la paz).

Hobbes y Rousseau difieren radicalmente en la relación entre el ser humano y la igualdad. Para el inglés, esta es una de las causas de la guerra (violencia) ${ }^{43}$, para el ginebrino es la esencia de la paz $^{44}$.

\section{Una alternativa ontológica imperfecta}

Ahora bien, desde la perspectiva que se viene proponiendo en el concepto de paz imperfecta, los seres humanos no somos ni esencialmente violentos, ni esencialmente pacíficos; somos primariamente conflictivos. Lo ontológico no es la violencia o la paz; es el conflicto ${ }^{45}$. Por tanto, urge un modelo ontológico imperfecto que fije su atención en las características, que abandone las esencias ${ }^{46}$ y que abandone los binomios conceptuales.

Tanto la paz como la violencia son construcciones culturales, históricas, y, por tanto, contingentes. Desde una perspectiva compleja que permite el reconocimiento de la convivencia de aspectos aparentemente antagónicos, en los seres humanos conviven, como ya he expresado anteriormente, comportamientos cooperativos y egoístas, altruistas y codiciosos, pacíficos y violentos. Ahora bien, ¿cuáles han sido predominantes a lo largo de la Historia de la humanidad? En varios trabajos hemos propuesto que los comportamientos considerados pacíficos han sido mayoritarios ${ }^{47}$. Es más, sostenemos que los cuidados (que son comportamientos que pueden relacionarse con la paz) han precedido a la justicia. Por tanto, los cuidados son habitus, estructuras estructuradas estructu-

42 Hans Kelsen, ¿Qué es la Justicia? (Barcelona: Planeta-Agostini, 1993), 69.

43 "And seeing every man is presumed to do all things in order to his own benefit, no man is a fit arbitrator in his own cause: and if he were never so fit, yet equity allowing to each party equal benefit, if one be admitted to be judge, the other is to be admitted also; and so the controversy, that is, the cause of war, remains, against the law of nature." (Hobbes, Leviathan, 96).

44 "Así resultó que, los más poderosos o los más miserables, hicieron de sus fuerzas o de sus necesidades una especie de derecho en beneficio de los demás, equivalente, según ellos, al derecho de propiedad, y que rota la igualdad, se siguió el más espantoso desorden, pues las usurpaciones de los ricos, los latrocinios de los pobres y las pasiones desenfrenadas de todos, ahogando el sentimiento de piedad natural y la voz débil aún de la justicia, convirtieron a los hombres en avaros, ambiciosos y malvados. Surgía entre el derecho del más fuerte y el del primer ocupante un conflicto perpetuo que sólo terminaba por medio de combates y matanzas (q). La sociedad naciente dio lugar al más horrible estado de guerra, y el género humano, envilecido y desolado, no pudiendo volver sobre sus pasos, ni renunciar a las desgraciadas adquisiciones hechas, y trabajando solamente en vergüenza suya, a causa del abuso de las facultades que le honran, se colocó al borde de su propia ruina." Jean-Jacques Rousseau, Discurso sobre el origen de la desigualdad (Elaleph.com, 1999) http://www.enxarxa.com/biblioteca/ROUSSEAU\%20Discurso\%20sobre\%20la\%20desigualdad. pdf, $(25 / 01 / 2020), 70$.

45 Marco A. Millán Campuzano, Hermenéutica de la paz y los conflictos (Cuautitlán Izcalli: E-dae, 2015 ), 2.

46 Jiménez Arenas, "Evolución humana y paz".

47 Jiménez Arenas, “Pax Homínida”; “Evolución humana y paz”; Jiménez Arenas y Muñoz Muñoz, La Paz, partera. 
rantes que dan sentido a nuestra vida y a nuestras acciones ${ }^{48}$. Así, existen habitus pacíficos ${ }^{49}$. En el caso de los seres humanos, nuestra propia fragilidad -intrínseca y ontológica - provoca unas interdependencias que hacen que los cuidados sean intensivos y permanentes a lo largo de nuestras vidas ${ }^{50}$.

Por tanto, parece claro que los modelos ontológicos se constituyen en andamiajes de los prejuicios y estos se alimentan de aquéllos. No obstante, no dejan de ser simplificaciones que no atienden a ese ser humano que hemos propuesto al principio: cambiante, complejo, contingente, histórico, mutable... En este sentido pienso en una alternativa: tratar de caracterizar a los seres humanos, evitando en la medida de lo posible (y siendo conscientes de que los prejuicios son inherentes a nuestra práctica) esos prejuicios preñados de violencia simbólica que con más frecuencia de lo deseable aparecen:

a. Antropocentrismo: El ser humano, culmen de la naturaleza

b. Etnocentrismo: Analizo en función de mi cultura

c. Androcentrismo: El hombre, medida de todas las cosas

d. Biacentrismo: El ser humano, violento por naturaleza

Por tanto, dentro de la caracterización demandada podemos proponer a los seres humanos como entes conflictivos, complejos, frágiles, capaces de hacer las paces y de infligir violencias aunque habituados a los cuidados.

\section{La paz imperfecta (y sistémica) ${ }^{51}$}

Imperfecto puede ser entendido como algo negativo, como algo defectuoso. Pero el castellano nos ofrece, dentro de su riqueza, la posibilidad de los tiempos verbales que denotan acciones inacabadas: imperfectos. $\mathrm{Y}$ ese es uno de los sentidos fundamentales del concepto paz imperfecta, su carácter procesual y contextual, en permanente construcción, perfectible. Además, se trata de una paz cotidiana, ubicua y que es responsabilidad de todas las entidades humanas.

Otra de las diferencias sustanciales que presenta la paz imperfecta es que no necesariamente depende de la violencia. La paz es una forma de transformación de los conflictos, y como he expresado anteriormente, los conflictos deben ser considerados una oportunidad, y la gestión pacífica de los mismos, una expresión de la creatividad humana. Los conflictos no son la antesala ineluctable de la violencia.

De esta forma, la paz se convierte en una forma de gestionar los conflictos que tiene sentido en sí misma y que no es exclusivamente una medida a tomar cuando la violencia ya se ha manifestado con toda su crudeza.

\footnotetext{
48 Pierre Bourdieu, Esquisse d’une théorie de la pratique. Précédé de "Trois études d’ethnologie kabyle” (Ginebra: Droz, 1972$), 178$.

49 Bolaños Carmona y Muñoz Muñoz, Los habitus de la paz.

50 Jiménez Arenas, "Complexity"; Irene Comins Mingol y Juan M. Jiménez Arenas, "Reflexiones filosófico-antropológicas en torno al cuidado como origen y fundamento de la justicia”, en Investigación para la paz: Teorías, prácticas y nuevos enfoques, eds. París A. Cabello Tijerina, Guillermina Díaz Pérez y Reyna L. Vázquez Gutiérrez (Valencia: Tirant lo Blanc, 2019).

51 Para un acercamiento más profundo a este concepto, recomiendo la obra de Muñoz, La paz imperfecta.
} 
La paz imperfecta se define entonces como todas las conductas, acciones, actitudes, comportamientos que tienden al desarrollo de las capacidades deseables de los seres humanos. Hablar de capacidades y no de necesidades no es azaroso ni caprichoso. Las necesidades remiten a carencias, mientras las capacidades reconocen la presencia potencial radicando el problema en el grado de desarrollo de las mismas. Cuando se alude a necesidades humanas emerge la figura de Abraham Maslow. Para el psicólogo estadounidense, las necesidades son jerárquicas y siguen un orden (fisiológicas, de seguridad, de afiliación, de reconocimiento y de autorrealización), de forma que hasta que no se han satisfecho las más básicas, el ser humano no se ocupa (o no se debería ocupar) de las otras ${ }^{52}$. Por esa razón, las necesidades humanas se articulan siguiendo una forma piramidal (Fig. 1). De cualquier forma, es relevante poner de manifiesto que Maslow teoriza sobre las motivaciones humanas.

Figura 1. Pirámide de necesidades según A. H. Maslow

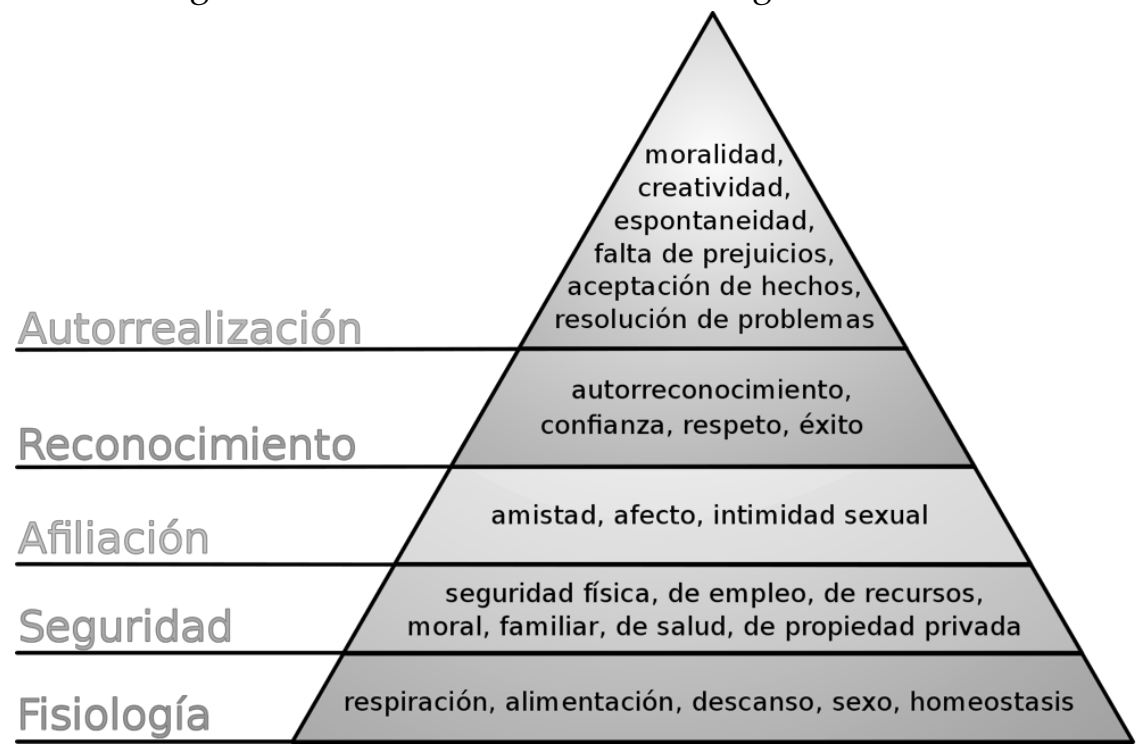

Fuente: https://commons.wikimedia.org/wiki/File:Pirámide_de_Maslow.svg (22 de diciembre de 2018).

Por otra parte, el concepto de capacidades ha sido tratado por muchas/os autoras/es de entre los que destacaré a Amartya Sen ${ }^{53}$, Martha C. Nussbaum ${ }^{54}$ y Manfred Max-Neef ${ }^{55}$. Este último nos ofrece una propuesta matricial y no jerárquica de las capacidades que se aviene muy bien con el planteamiento complejo y transdisciplinar de la paz imperfecta (Fig. 2).

\footnotetext{
52 Abraham H. Maslow, "A Theory of Human Motivation", Psychological Review, vol. 50, n. ${ }^{\circ} 4$ (1943).

53 Amartya Sen, Desarrollo y libertad (Barcelona: Planeta, 2000).

54 Martha C. Nussbaum, "Capacidades humanas y justicia social”, en Necesitar, desear, vivir. Sobre necesidades, desarrollo humano, crecimiento económico y sustentabilidad, ed. J. Riechmann (Madrid: Los Libros de la Catarata, 1995).

55 Manfred Max-Neef, Desarrollo a escala humana. Conceptos, aplicaciones y algunas reflexiones (Barcelona: Icaria editorial, 1994).
} 
Figura 2. Matriz de capacidades

POTENCIALIDADES HUMANAS

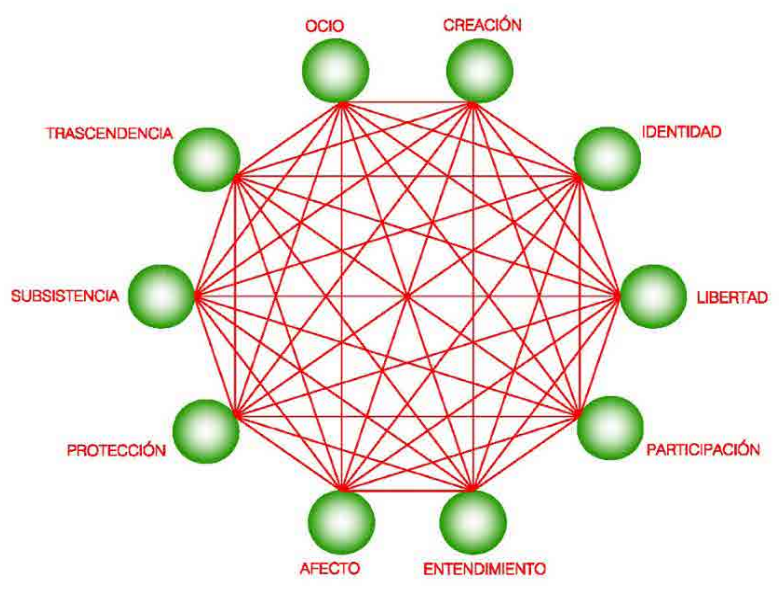

Fuente: Modificado a partir de Max-Neef, Desarrollo a escala humana.

De hecho, la propuesta del economista chileno se puede hacer aún más compleja puesto que suma a las once categorías axiológicas reflejadas en la figura 2 , cuatro categorías existenciales (ser, tener, hacer y estar). Las implicaciones de esta matriz se epitomizan en el carácter sistémico de la paz, esto es, como se interaccionan las diferentes instancias de la paz.

Ahora bien, y esto es clave para entender la propuesta universalista de Max-Neef, no se deben confundir las capacidades con los satisfactores de las mismas; proceso tremendamente complicado en un mundo transformado por un neoliberalismo cada vez más tendente al hiperconsumismo.

Desde una perspectiva histórica, con repercusiones epistemológicas, la consideración imperfecta de la paz permite visualizarla y visibilizarla en todo tiempo y espacio y por parte de todos los agentes (entidades humanas). Y esto, volviendo a una idea propuesta en el enunciado inicial de este artículo, supone abandonar la creencia de que solo a partir de los errores se puede aprender. Hablar de paz, sacarla a la luz, implica tomar conciencia de cómo la paz, el desarrollo de capacidades, ha sido una constante a lo largo de la historia y por tanto se convierten en referentes para minar la idea del ser humano violento y para la construcción de futuros diferentes.

Pero la consideración imperfecta de la paz también implica su convivencia con la violencia. Por muy grave y extendida que sea, la violencia tampoco es perfecta, tampoco ocupa todo el espacio o todo el tiempo. El carácter paradójico de la paz (y de la violencia) confiere a la paz el carácter de alter-utópica porque implica que no es necesario que desaparezcan todas las expresiones de la violencia para que podamos reconocer la paz. 
Otra cuestión básica desde la perspectiva de la investigación para la paz, y más concretamente de la paz imperfecta, es el reconocimiento de que todas las entidades humanas tienen capacidad para hacer las paces. Incluso aquéllas que hemos convertido en nuestros particulares leviatanes. Esta cuestión es sumamente importante y delicada porque implica romper con la lógica de enemigo y transmutarla en lógica de adversario/a. Los adversarios son legítimos, mientras que los enemigos no disfrutan de tal consideración. Es más, el enemigo es un objetivo a destruir. Mientras, el adversario es necesario para la realización de los diferentes proyectos ${ }^{56}$. El adversario emerge pues como una consecuencia del reconocimiento de la diferencia, de la otredad y de la interseccionalidad. El enemigo surge de una concepción dualista, excluyente, dogmática y patriarcal. En definitiva, forma parte del proyecto de la Modernidad.

Este cambio, tan relevante para la paz imperfecta y el giro, tiene consecuencias axiológicas, epistemológicas y ontológicas. Respecto a las primeras, y como nos ha legado el maestro Vicent Martínez Guzmán, que los otros, por muy violentos que sean considerados, disfruten de las mismas capacidades que nosotros nos permite exigir la rendición de cuentas. Incluso debemos ir más allá al reconocer sus comportamientos pacíficos ${ }^{57}$. Este tema es tremendamente delicado y provoca airados debates. No deviene en absolución, sino en demanda del cumplimiento de sus responsabilidades en la esfera del deber ser. Puesto que no se trata de una tara esencial sino de una toma de decisiones, las entidades que ejercen violencias pueden optar por hacer las paces. Paz y violencia conviven, se interrelacionan y son ejercidas por las mismas entidades humanas. Ahora bien, esta afirmación no es óbice para el reconocimiento de la asimetría en el ejercicio de la paz y la violencia. Es patente que hay entidades humanas que ejercen más violencia que otras. No obstante, que esto no empañe el reconocimiento de las paces que hacen.

Desde un punto de vista epistemológico, la convivencia de paz y violencia y la consideración de ambas como consecuencia de los conflictos, no lleva a un escenario en el que la paz no es, exclusivamente, dependiente de la violencia. Es más, la paz como práctica precede a la violencia e, incluso a la justicia ${ }^{58}$. Por tanto, desde la perspectiva de la paz imperfecta y el giro epistemológico, planteamos la posibilidad de conceptos de paz independientes y omnipresentes. Bajo mi punto de vista, la conjunción de estas dos características se dan en la

56 "[...] en tanto el antagonismo constituye una relación nosotros/ellos en la cual las dos partes son enemigas y no comparten ninguna base común, el agonismo establece una relación nosotros/ellos en que las partes en conflicto, cuando se admite que no existe una solución racional para su conflicto, se perciben a sí mismas como pertenecientes a la misma asociación política [...]. Es por eso que 'el adversario' constituye una categoría crucial para la política democrática." [Chantal Mouffe, En torno a lo político (Buenos Aires: Fondo de Cultura Económica, 2007), 27.

57 Un ejemplo clásico en España es Amancio Ortega, fundador y propietario de Inditex. El magnate gallego lleva a cabo donaciones periódicas. Una de las más conocidas fue el reemplazo de los instrumentos de detección de cáncer en centros sanitarios públicos españoles. Por supuesto que debería ser el Estado el encargado de impulsar estas acciones y que debería luchar contra las prácticas de ingeniería financiera y de deslocalización de la producción hacia lugares donde los costes (económicos) son menores, que suelen practicar esta clase de empresarios. Pero no es menos cierto que con dicha acción se están desarrollando las capacidades humanas deseables de muchas personas. No se trata de justificar ni de exculpar a Amancio Ortega, sino de exigirle que, siendo como es, capaz de contribuir al desarrollo de las capacidades humanas, esas acciones y conductas ocupen el mayor espacio público.

58 Jiménez Arenas, "Pax Homínida”; "Evolución humana”; Comins Mingol y Jiménez Arenas, "Reflexiones filosófico-antropológicas". 
paz imperfecta y la paz transracional ${ }^{59}$. Otras paces, como la paz negativa, la paz positiva $^{60}$ o la paz neutra ${ }^{61}$ son dependientes de las violencias directa, estructural y cultural, respectivamente. Por su parte, la paz liberal es - paradójicamenteexcesivamente dependiente de las instituciones ${ }^{62}$.

Por último, cabe recordar a modo de resumen y aún a expensas de repetir, algunas de las consecuencias ontológicas derivadas del cambio de enemigo a adversario. La primera, y principal, los seres humanos no somos ni violentos ni pacíficos por naturaleza. La segunda, derivada del anterior, considera a todos los seres humanos como capaces de hacer las paces. También de infligir violencias. La tercera, la paz es responsabilidad de todas las entidades humanas. La cuarta, los seres humanos debemos reconocernos en nuestra diversidad sin que ello conlleve discriminación. Esta, es una forma de violencia. La quinta, y última, todos los seres humanos tenemos poder, entendido como capacidad para transformar la realidad, y lo ejercemos.

\section{Del poder a la agencia pacifista}

El último de los ejes que articulan la paz imperfecta es el empoderamiento pacifista. Este no está exento de debate, incluso dentro de los autores que venimos trabajando bajo el paraguas de este concepto. Francisco Muñoz lo planteó, en un primer momento, como el vínculo entre la teoría con la práctica, porque ambas deben ir de la mano.

\section{¿Qué es el poder?}

Antes de abordar qué es el empoderamiento y la agencia pacifistas es fundamental detenerse por un instante en qué es el poder, la base de aquéllas. Como consideremos el poder va a ejercer una influencia capital en cómo caractericemos

59 "Transrational peace research is a relatively new term that we coined at the University of Innsbruck's UNESCO Chair for Peace Studies at the beginning of this millennium. It results from our research on different perceptions and interpretations of peace in history and culture. Principally, we found four major groups of interpretation, which we called the energetic, the moral, the modern and the postmodern peace families. Each circulates around a specific key value: energetic peace is all about harmony, the moral interpretation emphasizes justice, the modern understanding of peace calls for security, and the postmodern approach deals with the question of truth(s). Since none of these values appear isolated in social life, we tried to combine them in a holistic manner and identified the dynamic equilibrium of the four aspects as a larger concept of peace." [Wolfgang Dietrich, "A Brief Introduction into Transrational Peace Research and Elicitive Conflict Transformation”, Journal of Conflictology, vol. 5, n. ${ }^{\circ} 2$ (2014): 48].

60 "An extended concept of violence leads to an extended concept of peace. Just as a coin has two sides, one side alone being only one aspect of the coin, not the complete coin, peace also has two sides: absence of personal violence, and absence of structural violence. We shall refer to them as negative peace and positive peace respectively." [Johan Galtung, "Violence, Peace and Peace Research", Journal of Peace Research, vol. 6, n. 3 (1969): 183].

61 " $[\ldots]$ neutralizar los elementos violentos que habitan en los patrones que posee cada sociedad para organizar las relaciones entre los individuos, las familias, los grupos y la naturaleza." [Francisco Jiménez Bautista, "Paz neutra. Una ilustración del concepto", Revista de Paz y Conflictos, vol. 7 (2014): 22].

62 Véanse, p. ej.: Michael W. Doyle, "Kant, Liberal Legacies, and Foreign Affairs", Philosophy \& Public Affairs, vol. 12, n. ${ }^{\circ} 3$ (1983); Rudolph Rummel, "Libertarianism and International Violence", The Journal of Conflict Resolution, vol. 27, n. 1 (1983); Zeev Maoz y Nasrin Abdolali, "Regime Types and International Conflict, 1816-1976", The Journal of Conflict Resolution, vol. 33, (1989); John R. O’Neal y Bruce Russett, "Assessing the Liberal Peace with Alternative Specifications: Trade Still Reduces Conflict", Journal of Peace Research, vol. 36, n. ${ }^{\circ}$ (1999); Nils Petter Gleditsch, "Democracy and Peace", en Nils Petter Gleditsch: Pioneer in the Analysis of War and peace (Cham: Springer, 2015). 
al ser humano. Las conceptualizaciones clásicas del poder han transitado por el ejercicio de la violencia, las han considerado como externo y las han atribuido a unos pocos. Es por ello por lo que haré un recorrido por diferentes formas de entender el poder y, aplicando el giro epistemológico, encontraré aliadas/os para plantear una propuesta alternativa.

Siguiendo lo que nos propone el DLRAE, respecto al sustantivo "poder", tenemos las siguientes acepciones:

1. m. Dominio, imperio, facultad y jurisdicción que alguien tiene para mandar o ejecutar algo.

2. m. Gobierno de algunas comunidades políticas.

3. m. Acto o instrumento en que consta la facultad que alguien da a otra persona para que en lugar suyo y representándolo pueda ejecutar algo. U. m. en pl.

4. m. Posesión actual o tenencia de algo. Los autos están en poder del relator.

5. m. Fuerza, vigor, capacidad, posibilidad, poderío.

6. m. Suprema potestad rectora y coactiva del Estado. ${ }^{63}$

Como se puede comprobar, las definiciones (que no conceptos) están enmarcadas en la consideración "tradicional" del poder. Me interesa resaltar la primera, la segunda, la quinta y la sexta. En la primera se puede entrever, aunque no claramente, que el poder es la facultad para ejecutar. Y eso no es privativo de ninguna entidad humana. Sin embargo, se ve desdibujada por la convivencia con términos tales como dominio, imperio y mandar, que denota un poder vertical y coercitivo. La segunda y la sexta remiten al Estado y sus instituciones. Mientras la quinta, remite a características consideradas masculinas, lo que denota su carácter heteropatriarcal.

Sin embargo, el escenario se torna algo diferente si atendemos al "poder" como verbo:

1. tr. Tener expedita la facultad o potencia de hacer algo.

2. tr. Tener facilidad, tiempo o lugar de hacer algo. U. m. con neg.

3. tr. coloq. Tener más fuerza que alguien, vencerlo luchando cuerpo a cuerpo.

4. intr. Ser más fuerte que alguien, ser capaz de vencerlo.

5. intr. Aguantar o soportar algo o a alguien que producen rechazo. U. con el verbo en forma negativa.

6. intr. Ser contingente o posible que suceda algo. ${ }^{64}$

$\mathrm{Al}$ menos las acepciones primera, segunda y sexta, remiten a capacidades activas y, eventualmente, transformadoras de los seres humanos.

Retrocediendo en el tiempo dibujaré una propuesta diacrónica para ver cómo ha evolucionado la idea de poder. Comenzaré por Maquiavelo ${ }^{65}$. Para el florentino, el poder estaba encarnado en el poder político y su representación era la

63 Real Academia Española, Diccionario de la lengua española, 23. ${ }^{\text {a }}$ ed. https://dle.rae.es

64 Ibíd.

65 Nicolás Maquiavelo, El príncipe (Barcelona: Círculo de Lectores, 1980). 
figura del princeps (el primero entre iguales). Según el preceptor de Lorenzo de Médici hay tres vías para acceder al poder: las armas, la intriga o la ayuda del pueblo. Sin embargo, el origen del poder está en las primeras.

El contractualista Thomas Hobbes, al igual que Maquiavelo, concibe el poder como poder político ${ }^{66}$. El gran cambio viene dado porque su representación pasa a ser detentada por el Estado; absolutista. Como ya he puesto de manifiesto anteriormente, la guerra (violencia) y el egoísmo (ansia de poder) son inherentes a los seres humanos. Por tanto, el Estado (el soberano) debe imponer, ante esta situación, el poder cedido por los súbditos para generar paz y orden. De esta forma se consigue el encauzamiento de la violencia. Una vez se produce el pacto, éste no puede ser ni cambiado ni revocado.

John Locke va a introducir una serie de cambios importantes en la concepción del poder ${ }^{67}$. En primer lugar, el Estado actúa como mecanismo regulador. Los seres humanos, pacíficos por naturaleza, se organizan y ceden al Estado "su" poder de manera libre (el resaltado es mío) lo que legitima al Estado que materializa dicho acto en un documento jurídico (constitución). El Estado está obligado a mantener el interés colectivo frente a los intentos de monopolio del poder por parte de individuos o facciones. El orden legítimo, el del Estado, no crea violencia ${ }^{68}$. El Estado no es coercitivo, el poder recae en el respeto y mantenimiento de las leyes comunes y si se excede o no cumple con su parte del contrato, se le puede pedir cuentas. El Estado tiene, por tanto, límites.

Ya en el siglo XIX, para el marxismo clásico, es el poder lo que provoca la desigualdad y la asimetría. El Estado se convierte en instrumento de coerción al servicio de la clase dominante y el fin último es el de oprimir a las otras clases. El estado-nación es la materialización del proyecto político burgués y por tanto sirve a los intereses de la nueva clase dominante. El poder político emerge, pues, como "la violencia organizada de una clase para la opresión de otra" ${ }^{69}$. El poder, aliena. El proletariado, la clase dominada, si quiere defender sus intereses, ha de luchar por la conquista del poder, que utilizará para crear una nueva sociedad sin clases.

Abundando en la propuesta de Marx y Engels, tenemos uno de los conceptos más fértiles de las ciencias sociales: el de hegemonía ${ }^{70}$. Se trata del control por parte de la clase dominante y representa la ortodoxia, la oficialidad. Contribuye a que las clases dominadas acepten su rol, delimitado por las dominadoras e implica la aceptación tácita por ambos grupos. La alternativa pasa porque los dominados tomen conciencia de la capacidad que tienen para transformar la realidad y creen una nueva hegemonía (contrapoder).

\footnotetext{
66 Hobbes, Leviathan.

67 John Locke, Ensayo sobre el entendimiento humano; Escritos sobre la tolerancia; Pensamientos sobre la educación (Madrid: Editorial Gredos, 2013).

68 Posteriormente, Weber planteará que el Estado detenta monopolio del uso legítimo de la violencia. [Max Weber, Economía y sociedad. Esbozo de sociología comprensiva (Madrid: Fondo de Cultura Económica, 2008), 43-44]. Ahora bien, una pregunta pertinente es: ¿es legítima la violencia? Bajo mi punto de vista no, no hay violencia legítima puesto que es injusta, aunque sí legal.

69 Karl Marx y Friedrich Engels, Obras escogidas. Manifiesto comunista (Madrid: Akal, 1975), 43.

70 Antonio Gramsci, Escritos políticos (1917-1933) (México: Siglo XXI, 1991).
} 
Como vimos al comienzo de este apartado, el poder puede ser sustantivo y verbo. En mi opinión, el segundo resulta de mayor interés para el objetivo de este artículo porque indica acción, capacidad ${ }^{71}$. Y en este sentido, Hannah Arendt nos ha legado una propuesta crítica y, hasta cierto punto, revolucionaria. La acción es la principal actividad política de los seres humanos. Arendt desafía al pensamiento político, que concibe al poder como la "posibilidad de imponer en cada caso la propia voluntad al comportamiento de los demás"72. Esto no sería poder, es violencia. No obstante, en la clásica asimilación entre poder y violencia no hay distingos entre filósofos y políticos de derecha y de izquierda (con la excepción de Locke, del que hemos hablado anteriormente, y de Kropotkin ${ }^{73}$ ). Por tanto, urge una propuesta alternativa del poder que se "corresponde a la capacidad humana no solo de actuar sino de actuar en concierto. El poder no es nunca una propiedad de un individuo; pertenece al grupo y existe sólo mientras éste no se desintegra" ${ }^{\prime 74}$. En este último sentido, la pensadora alemana coincide con Michael Mann, para quien el poder también ${ }^{75}$ deriva de la cooperación y la construcción de redes, destacando el carácter colectivo del poder ${ }^{76}$. No obstante, este mismo autor nos advierte que "el [poder] distributivo y el [poder] colectivo, el explotador y el funcional, actúan simultáneamente y están entrelazados" ${ }^{\prime 77}$.

A pesar de la relevancia de Arendt para la investigación para la paz, quizás haya sido Foucault el pensador que más ha contribuido a un redefinir el concepto de poder. Para el sociólogo francés, el poder seguía estando vinculado a la fuerza, como relaciones de las mismas ${ }^{78}$. El poder no se tiene: se ejerce y no es una propiedad, es estrategias y actos ${ }^{79}$. El poder no está solo en el Estado. Es omnipresente situándose en múltiples loci y alcanza a todas las entidades humanas y a todas sus instancias. El poder es panóptico ${ }^{80}$ y capilar ${ }^{81}$. No está supeditado a lo económico o a lo político y, por tanto, debemos abandonar la propuesta segmentada del mismo. Ahora bien, desde una perspectiva ontológica del poder, este es represor ${ }^{82}$. Por tanto, Foucault, a pesar de no participar del giro ontológico, nos proporciona puntos de fuga que debemos reinterpretar desde la perspectiva de la investigación para la paz que vengo proponiendo. En breve volveré sobre este particular.

71 La acción es la principal actividad política de los seres humanos. [Hannah Arendt, ¿Qué es la política? (Barcelona: Paidós, 1997), 151.]

72 Jürgen Habermas, Perfiles filosófico-políticos (Madrid: Taurus, 2000), 205.

73 Piotr Kropotkin, Mutual aid: A Factor of Evolution (Manchester: Extending Horizons Books, 2005).

74 Hannah Arendt, Sobre la violencia (México: Joaquín Mortiz, 1970), 41.

75 El uso del adverbio también es muy importante en este caso puesto que denota la coexistencia de diferentes formas de entender el poder. El hecho de que desde la investigación para la paz se demande un giro en dicho concepto no debe opacar la existencia del "otro" poder.

76 Michael Mann, Las fuentes del poder social, vol. 1 (Madrid: Alianza, 1991), 21.

77 Ibíd.

78 Michel Foucault, Microfísica del poder (Madrid: Ediciones de la Piqueta, 1980), 136.

79 Ibíd., 135.

80 Ibíd., 118-119.

81 Ibíd., 142.

82 Ibíd., 135. 


\section{El poder como paz. Empoderamiento y agencia pacifistas}

El único autor clásico de la investigación para la paz que ha tratado el tema del poder ha sido Kenneth Boulding. Efectivamente, en su libro Las tres caras del poder $^{83}$ propone una tríada de poderes, dos de los cuales no son, necesariamente, violentos y uno es, deliberadamente, pacífico. El poder destructivo se vale de la amenaza y sería violento; el poder productivo se basa en el intercambio y puede no ser violento aunque, en múltiples ocasiones, genera violencia estructural ${ }^{84}$; y el poder integrativo que es pacífico y cuya máxima expresión sería el amor, entendido este como una relación deliberada, intencional y afectiva para promover el bienestar ${ }^{85}$.

El aspecto interesante que aporta Boulding, también contemplado por Arendt, es que el poder se puede entender como potencial para producir un cambio, pero no solo de forma individual (es decir, conseguir lo que uno quiere, como generalmente se entiende), sino que es fundamental y mayoritariamente una cuestión colectiva.

Retornando a la investigación para la paz, es capital participar en el debate sobre el poder, concepto central de las Ciencias Sociales. Pero, ¿qué poder? ¿Sobre qué "hombros de gigantes" debemos fundamentar el giro epistemológico aplicado al concepto de poder?

De Locke podemos rescatar la idea de que el poder político, el Estado, no es exclusivamente coercitivo; es más, debe procurar el bien común y dejar de lado el ejercicio de la violencia, por ilegítima. De Foucault, que es capilar y reticular y alcanza todas las instancias, que es acto y deja de ser un elemento exógeno y distante. De Mann, que también es colectivo y transformador. De Boulding, que el amor es una manifestación de poder. Y de Arendt, que la imposición es violencia y que el poder permite llegar a acuerdos.

El poder emerge, desde la perspectiva de la investigación para la paz, como la capacidad que detentan todas las entidades humanas para transformar la realidad y tomar las riendas de sus propias existencias. Uniendo lo capilar, de Foucault, y lo colectivo de Mann y Arendt, el poder también está en la creación de redes. En la colaboración, en la cooperación, en la compartición. Y desde un punto de vista epistemológico, en la transdisciplinariedad. El poder no se conquista, se ejerce. El poder es también, poder-hacer ${ }^{86}$. No obstante, es relevante poner de manifiesto dos cuestiones para no caer en la ingenuidad. La primera, que el hecho de que todas las entidades humanas tengan poder no significa que

83 Kenneth Boulding, Las tres caras del poder (Barcelona: Paidós, 1993).

84 Galtung, "Violence, Peace".

85 Francisco A. Muñoz Muñoz y Juan M. Jiménez Arenas, Ordo Amoris. El poder del amor en la construcción de paz (Granada: Editorial de la Universidad de Granada, en prensa).

86 John Holloway, Cambiar el mundo sin tomar el poder. El significado de la revolución hoy (Caracas/Valencia: Vadell Hermanos Editores, 2005); Marina Stussi García, "El poder y las respuestas ciudadanas de compensación de asimetrías. Estudio sobre el concepto del poder y su importancia en el desarrollo de iniciativas ciudadanas en la ciudad de Granada para la transformación social hacia una sociedad más pacífica" (tesis de maestría [entiendo el cambio de denominación, pero en España el nombre oficial es Trabajo Fin de Máster] en Cultura de Paz, Conflictos, Educación y Derechos Humanos, Universidad de Granada, 2017). 
todas lo ejerzan de la misma manera (ni cualitativa ni cuantitativamente). Hay tendencias que tratan de limitar e impedir el desarrollo de dicha capacidad. De entre ellas destacaré los habitus y la hegemonía. La segunda, es que, aunque considerada violencia por Arendt, hoy día todavía se considera poder al ejercicio de la imposición, la dominación y la subordinación.

El siguiente paso es el empoderamiento. Palabra muy en boga en los últimos años y cuyo uso ha sido confuso cuando no contrario a su origen. En primer lugar, empoderamiento no remite a un modelo prescriptivo en el experto que transfiere conocimientos, modelos, técnicas, etc. ${ }^{87}$. El empoderamiento surge de la toma de conciencia. Por supuesto, puede haber individuos, colectivos, situaciones que actúen como catalizadores, facilitadores, pero se trata de un proceso interno, como se deduce de dos de las definiciones más clásicas de empoderamiento $^{88}$. Efectivamente, tal y como nos proponen Rappaport y Adams, se trata de un proceso en el que los individuos y las comunidades ganan confianza y toman decisiones respecto a sus vidas. Sobre todo, aquellas personas o colectivos marginalizados o vulnerabilizados. Más aún, en el caso de Adams, se plantea la maximización de la calidad de sus vidas. Esta última cuestión entronca directamente con la propuesta de paz desde la paz imperfecta (desarrollo de las capacidades humanas deseables). No obstante, en ningún momento se habla de paz. Por tanto, puede haber empoderamiento que implique violencia. Por ello es clave definir el empoderamiento pacifista como la toma de conciencia de la capacidad que tiene la paz para transformar la realidad de forma que se incrementen o mantengan las capacidades humanas deseables en pos de mayor autonomía y autodeterminación. También podemos proponer que el empoderamiento pacifista implique que la paz ocupe cada vez mayor espacio personal, público y político ${ }^{89}$.

Para finalizar, el poder-hacer de Holloway, aplicado a la investigación para la paz por Stussi García, nos conduce a la cuestión de la agencia: de la toma de conciencia a la acción. Siguiendo a Malmström, la agencia es una capacidad universal para actuar ${ }^{90}$, pero que está socio-culturalmente mediada ${ }^{91}$. Dicho de otra manera, las capacidades personales [también colectivas] para sentir, pensar, meditar, intentar y actuar en las relaciones sociales particulares y los contextos históricos en los que las/os agentes viven sus vidas ${ }^{92}$. Por tanto, la capacidad de

87 John Paul Lederach, Building peace: sustainable reconciliation in divided societies (Washington: United States Institute of Peace Press, 1997).

88 "Empowerment is viewed as a process: the mechanism by which people, organizations, and communities gain mastery over their lives." [Julian Rappaport, "Studies in Empowerment: Introduction to the Issue", Prevention in Human Services, vol. 3, n. ${ }^{\text {os }} 2-3$ (1984): 3.]; "Empowerment: the capacity of individuals, groups and/or communities to take control of their circumstances, exercise power and achieve their own goals, and the process by which, individually and collectively, they are able to help themselves and others to maximize the quality of their lives." [Robert Adams, Empowerment, Participation and Social Work (New York: Palgrave Macmillan, 2008), xvi.]

89 Paula A. Valencia Londoño, Susana Pérez-Gallart Mingrone y Omar Mancera González (eds.), Empoderamiento pacifista (Medellín - Granada: Sello Editorial de la Universidad de Medellín - Editorial de la Universidad de Granada, 2017).

90 Arendt, ¿Qué es la política?.

91 M. Frederika Malmström, "Gender, agency, and embodiment theories in relation to space", Egypt/Monde Arab, vol. 3, n. 9 (2012): 24.

92 Ibíd. 
agencia es también contextual, histórica y contingente. Esto es, a pesar de ser una característica universal (forma parte de la ontología del ser humano) se manifiesta de diferentes formas en función de las circunstancias. La cuestión clave es que los contextos no permiten que todas las entidades humanas actúen de la misma forma. Hay individuos y colectivos destinados a actuar, a poder-hacer, en mayor y más profunda medida. La agencia se aprende. Sobre todo, si tenemos en cuenta el sentido pedagógico de adquisición de virtudes morales mediante la coordinación de conductas (externas) y disposición (internas) que Aristóteles confirió a la hexis, el concepto que posteriormente daría origen a habitus. Se trata, pues, de un esfuerzo de reorientación en sentidos determinados ${ }^{93}$, intencional y dirigido por las entidades humanas que dominan. Por lo anteriormente expuesto, propongo que la combinación entre habitus y hegemonía provoca asimetrías en las capacidades para actuar, en la agencia. Ahora bien, por muy estructurados y estructurantes que sean ambos conceptos, las estructuras permiten márgenes para la transformación. Y para ello es fundamental el carácter hologramático de la realidad que, recuerdo, indica la capacidad de incidencia en el todo que tiene cualquier acción, por pequeña que sea ${ }^{94}$.

El carácter contextual, socio-cultural, de la agencia debe concientizarnos de los peligros de la paz. La paz imperfecta presenta entre sus características conseguir el máximo desarrollo humano posible. Pero los/as hegemónicos/as son contrarios/as al desorden, entendido como cuestionamiento de un statu quo inequitativo, pero que les beneficia, y la construcción de condiciones dignas para los/as marginalizados/as. Y en ese sentido, Colombia nos nutre de demasiados ejemplos negativos. La agencia de la paz, en cuanto transformación pacífica de los conflictos, se está produciendo con un altísimo coste humano ${ }^{95}$. Y obviamente, la paz y su investigación no necesitan mártires. Los ejemplos deletéreos deben ser erradicados o, en todo caso, convertirse en aprendizajes para encontrar diferentes caminos para la paz. No se trata de ser conformistas, sino de conservar lo más preciado de los seres humanos: la vida.

\section{CONCLUSIÓN}

Desde la perspectiva de la paz imperfecta, esto es, desde un planteamiento inacabado, en permanente construcción, resulta difícil, por no decir imposible, arribar a una conclusión. Este último término remite a una investigación terminada; a lo que se da por verdadero. Por el contrario, desde la propuesta que precede a estas líneas finales, el empoderamiento y la agencia pacifistas se

93 Saba Mahmood, "Feminist Theory, Agency, and the Liberatory Subject: Some Reflections on the Islamic Revival in Egypt", Temenos, vol. 42, n. $^{\circ} 1$ (2006): 54

94 Morin, Introducción.

95 Bibiana Moreno, Alarma por los continuos asesinatos a defensores de derechos humanos en Colombia (Noticias ONU. Mirada Global. Historias Humanas, 2019) https://news.un.org/es/story/2019/05/1455752 (20/01/2020). 
convierten en nuevos cruces y senderos. En lugares de encuentro y de intercambio en los que se honra a la paz imperfecta como proyecto colectivo al que se pueden sumar todas las personas que se sientan cómodas en los enfoques trans-, hologramáticos, rizomáticos, vasocomunicados, consensuados y paradójicos. Ahora bien, si por algo inicié esta reflexión es porque considero que no hay paz sin agencia. La paz y el poder se unen para convertirse en acciones que permiten transformar la realidad de manera que se puedan desarrollar las capacidades humanas deseables, dentro de un contexto concreto. Y para ello es fundamental rescatar la filosofía - para hacer las paces - subyacente al poder tal y como lo concibe Hannah Arendt. Por tanto, en vez de concluir debemos tomar impulso para que la paz ocupe cada vez un mayor espacio personal, público y político. Y esto no es una medida del empoderamiento pacifista, sino una consecuencia de la agencia pacifista.

Agradecimientos: Esta investigación se ha podido realizar gracias al grupo de investigación HUM-607 de la Junta de Andalucía (España). El autor agradece a las editoras del presente volumen por su invitación a participar en el mismo y a los/as revisores/as de este artículo por sus útiles y acertados comentarios que, sin lugar a dudas, han mejorado el contenido y la claridad expositiva del mismo.

\section{REFERENCIAS}

Adams, Robert. Empowerment, Participation and Social Work. New York: Palgrave Macmillan, 2008.

Alfaro Pareja, Francisco. "Capacidades para la paz en las negociaciones para el reconocimiento de la Independencia de Venezuela por parte de España (1833 y 1846)", Revista de Paz y Conflictos 7 (2014): 175-194.

Alfaro Pareja, Francisco. La historia oculta de la Independencia de Venezuela: De la guerra idealizada a la paz imperfecta. Caracas: Editorial Alfa, 2016.

Arendt, Hannah. Sobre la violencia. México: Joaquín Mortiz, 1970.

Arendt, Hannah. ¿Qué es la política? Barcelona: Paidós, 1997.

Bolaños Carmona, Jorge y Francisco A. Muñoz eds. Los habitus de la paz. Teorías y prácticas de la paz imperfecta. Granada: Editorial de la Universidad de Granada, 2011.

Boulding, Kenneth. Las tres caras del poder. Barcelona: Paidós, 1993.

Bourdieu, Pierre. Esquisse d'une théorie de la pratique. Précédé de "Trois études d'ethnologie kabyle". Ginebra: Droz, 1972.

Comins Mingol, Irene y Juan M. Jiménez Arenas. “Reflexiones filosófico-antropológicas en torno al cuidado como origen y fundamento de la justicia". En Investigación para la paz: Teorías, prácticas y nuevos enfoques, editado por París A. Cabello Tijerina, Guillermina Díaz Pérez y Reyna L. Vázquez Gutiérrez. Valencia: Tirant lo Blanc, 2019, 82-103.

Corral, Miguel G. La ciencia sigue sufriendo presiones políticas. Madrid: El Mundo, 2014. http://www. elmundo.es/ciencia/2014/05/26/537f9b75ca474195148b4575.html (26 de mayo, 2014).

Delanty, Gerard. "The cosmopolitan imagination: critical cosmopolitanism and social theory". The British Journal of Sociology 57, n. ${ }^{\circ} 1$ (2006): 25-47.

Deleuze, Gilles y Félix Guattari. Mil mesetas. Capitalismo y esquizofrenia. Valencia: Pre-Textos, 2008.

Di Bernardi Luft, Caroline, Guido Nolte y Joydeep Bhattacharya. "High-Learners Present Larger Mid-Frontal Theta Power and Connectivity in Response to Incorrect Performance Feedback". Journal of Neuroscience 33, n.o 5 (2013): 2029-2038.

Dietrich, Wolfgang "A Brief Introduction into Transrational Peace Research and Elicitive Conflict Transformation". Journal of Conflictology 5, n. ${ }^{\circ} 2$ (2014), 48-57.

Doyle, Michael. "Kant, Liberal Legacies, and Foreign Affairs". Philosophy \& Public Affairs 12, n. 3 
(1983): 205-235.

Dussel, Enrique. Transmodernidad e interculturalidad (Interpretación desde la Filosofía de la Liberación). Ciudad de México, 2005. https://red.pucp.edu.pe/wp-content/uploads/biblioteca/090514. $\operatorname{pdf}(13 / 05 / 14)$.

Ferrater Mora, José. “Ontología”. En Diccionario de Filosofía 3, coordinado por José Ferrater Mora, nueva edición revisada, aumentada y actualizada por J. M. Terricabas, bajo la supervisión de P. Cohn Ferrater Mora. Barcelona: Círculo de Lectores, 2001, 2622-2628.

Foucault, Michel. Microfísica del poder. Madrid: Ediciones de la Piqueta, 1980.

Galtung, Johan. "Violence, Peace and Peace Research" Journal of Peace Research 6, n. 3 (1969): 167-191.

Gil Martínez, Joaquín y Ramón A. Feenstra. “La sociedad civil en Gramsci desde una perspectiva antropológica". En La imagen del ser humano. Historia, Literatura y Hermenéutica, editado por Javier San Martín y Tomás Domingo Moratalla. Madrid: Biblioteca Nueva, 2011, 29-38.

Gleditsch, Nils Petter. "Democracy and Peace". En Nils Petter Gleditsch: Pioneer in the Analysis of War and peace. Cham: Springer, 2015, 61-90.

Gramsci, Antonio. Escritos políticos (1917-1933). México: Siglo XXI, 1991.

Grosz, Elizabeth. Time Travels. Feminism, Nature, Power. Sydney: Allen \& Unwin, 2004.

Habermas, Jürgen. Perfiles filosófico-políticos. Madrid: Taurus, 2000.

Haraway, Donna J. Simians, Cyborgs, and Women. The Reinvention of Nature. New York: Routledge, Taylor and Francis, 1991.

Hernández Arteaga, Isabel, Luna Hernández, José A. y Cadena Chala, Martha C. “Cultura de Paz: Una Construcción educativa aporte teórico". Revista Historia de la Educación Latinoamericana 19, n. 28 (2017): 149-172. https://doi.org/10.19053/01227238.5596

Histed, Mark H., Anitha Pasupathy y Earl K. Miller. "Learning Substrates in the Primate Prefrontal Cortex and Striatum: Sustained Activity Related to Successful Actions". Neuron 63, n. 2 (2009): 244-253.

Hobbes, Thomas. Leviathan or The Matter, Forme, \& Power of a Common-wealth Ecclesiasticall and Civil. London, Andrew Crooke, 1651. [Preparado para el archivo de la Historia del Pensamiento Económico de la Universidad de McMaster por Rod Hay].

Holloway, John. Cambiar el mundo sin tomar el poder. El significado de la revolución hoy. Caracas/ Valencia: Vadell Hermanos Editores, 2005.

Ibn Jaldun. Introducción a la Historia. Sevilla: Editoriales Andaluzas Unidas, 1985.

Jiménez Arenas, Juan M. "Pax Homínida. Una aproximación imperfecta a la evolución humana". En Los habitus de la paz. Teorías y prácticas de la paz imperfecta, editado por Jorge Bolaños Carmona y Francisco A. Muñoz. Granada: Editorial de la Universidad de Granada, 2011, 65-93.

Jiménez Arenas, Juan M. “Complexity, Cooperation and Childhood: An Evolutionary Perspective”. En Children, Spaces and Identity, editado por Margarita Sánchez Romero, Eva Alarcón García y Gonzalo Aranda Jiménez. Oxford: Oxbow Books, 2015, 26-39.

Jiménez Arenas, Juan M. Evolución humana y paz. Una aproximación desde la teoría y la práctica. Vínculos de Historia n. ${ }^{\circ}$ 7, (2018): 15-36.

Jiménez Arenas, Juan M. y Francisco A. Muñoz Muñoz eds. La Paz, partera de la historia. Granada: Editorial de la Universidad de Granada, 2013.

Jiménez Bautista, Francisco. "Paz neutra. Una ilustración del concepto". Revista de Paz y Conflictos 7 (2014): 19-52.

Kelsen, Hans. ¿Qué es la Justicia?Barcelona: Planeta-Agostini, 1993.

Kropotkin, Piotr. Mutual aid: A Factor of Evolution. Manchester: Extending Horizons Books, 2005.

Lederach, John Paul. Building peace: sustainable reconciliation in divided societies. Washington: United States Institute of Peace Press, 1997.

Locke, John. Ensayo sobre el entendimiento humano; Escritos sobre la tolerancia; Pensamientos sobre la educación. Madrid: Editorial Gredos, 2013.

Mahmood, Saba. "Feminist Theory, Agency, and the Liberatory Subject: Some Reflections on the Islamic Revival in Egypt". Temenos 42, n. 1 (2006): 31-71.

Maldonado, Carlos Eduardo. Significado e impacto social de las ciencias de la complejidad. Bogotá: 
Ediciones desde abajo, 2013.

Malmström, M. Frederika. "Gender, agency, and embodiment theories in relation to space". Egypt/ Monde Arab 3, n. 9 [Gouvernance locale dans le monde arabe et en Méditerranée: Quel rôle pour les femmes?, editado por Sylvette Denèfle y Safaa Monqid], (2012): 21-35.

Mann, Michael. Las fuentes del poder social, vol. 1. Madrid: Alianza, 1991.

Maoz, Zeev y Nasrin Abdolali. "Regime Types and International Conflict, 1816-1976". The Journal of Conflict Resolution 33 (1989): 3-35.

Maquiavelo, Nicolás. El príncipe. Barcelona: Círculo de Lectores, 1980.

Marx, Karl y Friedrich Engels. Obras escogidas. Manifiesto comunista. Madrid: Akal, 1975.

Martínez Guzmán, Vicent. Filosofía para hacer las paces. Barcelona: Icaria, 2001.

Maslow, Abraham H. "A Theory of Human Motivation". Psychological Review 50, n. 4 (1943): 370-396.

Max-Neef, Manfred. Desarrollo a Escala Humana. Conceptos, aplicaciones y algunas reflexiones. Barcelona: Icaria editorial, 1994.

Millán Campuzano, Marco A. Hermenéutica de la paz y los conflictos. Cuautitlán Izcalli: E-dae, 2015.

Moreno, Bibiana. Alarma por los continuos asesinatos a defensores de derechos humanos en Colombia. Noticias ONU. Mirada Global. Historias Humanas, 2019. https://news.un.org/es/ story/2019/05/1455752 (20/01/2020).

Morin, Edgar. Introducción al pensamiento complejo. Barcelona: Gedisa, 1998.

Mouffe, Chantal. En torno a lo político. Buenos Aires: Fondo de Cultura Económica, 2007).

Muñoz Muñoz, Francisco A., ed. La paz imperfecta. Granada: Editorial de la Universidad de Granada, 2001.

Muñoz, Francisco A. “La paz imperfecta ante un universo en conflicto”. En La paz imperfecta, editado por Francisco A. Muñoz. Granada: Editorial de la Universidad de Granada, 2001.

Muñoz Muñoz, Francisco A. y Beatriz Molina Rueda, eds. Cosmovisiones de Paz en el Mediterráneo antiguo y medieval. Granada: Editorial de la Universidad de Granada, 1998.

Muñoz Muñoz, Francisco A. y Mario López Martínez, eds. Historia de la paz: tiempos, espacios y actores. Granada: Editorial de la Universidad de Granada, 2000.

Muñoz Muñoz, Francisco A. y Carmelo Pérez Beltrán, eds. Experiencias de Paz en el Mediterráneo. Granada: Editorial de la Universidad de Granada, 2003.

Muñoz, Francisco A. y Beatriz Molina Rueda. “Una Cultura de Paz compleja y conflictiva. La búsqueda de equilibrios dinámicos". Revista Paz y Conflictos n. 3 (2010): 44-61.

Muñoz Muñoz, Francisco A. y Juan M. Jiménez Arenas. “Histoire et recherche pour la paix. Expériences autour de la Méditerranée. Cahiers de la Méditerranée n. ${ }^{\circ} 91$ (2015): 165-178.

Muñoz Muñoz Francisco A., y Juan M. Jiménez Arenas. Ordo Amoris. El poder del amor en la construcción de paz. Granada: Editorial de la Universidad de Granada, en prensa.

Nussbaum, Martha C. "Capacidades humanas y justicia social". En Necesitar, desear, vivir. Sobre necesidades, desarrollo humano, crecimiento económico y sustentabilidad, editado por. J. Riechmann. Madrid: Los Libros de la Catarata, 1995, 43-104.

O'Neal, John R. y Bruce Russett. "Assessing the Liberal Peace with Alternative Specifications: Trade Still Reduces Conflict". Journal of Peace Research 36, n. ${ }^{\circ} 1$ (1999): 423-442.

Rappaport, Julian. "Studies in Empowerment: Introduction to the Issue". Prevention in Human Services 3, n. ${ }^{\text {os } 2-3 ~(1984): ~ 1-7 . ~}$

Rodríguez Magda, Rosa María. “Transmodernidad: La globalización como totalidad transmoderna". Revista Observaciones Filosóficas, n. ${ }^{\circ} 4$ (2007), www.observacionesfilosoficas.net/ latransmodernidadlaglo.html (13/05/14).

Rodríguez Magda, Rosa María. “Transmodernidad: un nuevo paradigma”. Transmodernity: Journal of Peripheral Cultural Production of the Luso-Hispanic World 1, n. 1 (2011): 1-13.

Rousseau, Jean Jacques. Discurso sobre el origen de la desigualdad. Elaleph.com, 1999. http://www. enxarxa.com/biblioteca/ROUSSEAU\%20Discurso\%20sobre\%20la\%20desigualdad.pdf, $(25 / 01 / 2020)$.

Ruelle, David. Azar y Caos. Madrid: Alianza, 1993.

Rummel, Rudolph. "Libertarianism and International Violence". The Journal of Conflict Resolution 27, n. ${ }^{\circ} 1$ (1983): 27-71. 
Sánchez Cazorla, Jesús. "Ciencia y tecnología para la paz”. En Ciencia, tecnología y sociedad. Contribuciones para una cultura de la paz, editado por F. Javier Rodríguez Alcázar, Rosa M. Medina Doménech y Jesús A. Sánchez Cazorla. Granada: Editorial de la Universidad de Granada, 1997, 15-47.

Scheffer, Marten. "The forgotten half of scientific thinking". Proceedings of the National Academy of Sciences 111, n. ${ }^{\circ} 17$ (2011): 6119.

Sen, Amartya. Desarrollo y libertad. Barcelona: Planeta, 2000.

Stussi García, Marina. "El poder y las respuestas ciudadanas de compensación de asimetrías. Estudio sobre el concepto del poder y su importancia en el desarrollo de iniciativas ciudadanas en la ciudad de Granada para la transformación social hacia una sociedad más pacífica". Tesis de maestría en Cultura de Paz, Conflictos, Educación y Derechos Humanos, Universidad de Granada, 2017.

UNESCO, Conferencia Mundial sobre la Educación Superior. La educación superior en el siglo XXI. Visión y Acción, 1998.http://unesdoc.unesco.org/images/0011/001136/113602So.pdf (13/05/2014).

Uzzi, Brian, Satyam Mukherjee, Michael Stringery Ben Jones. "Atypical Combinations and Scientific Impact". Science 342, n. ${ }^{\circ} 6157$ (2013): 468-472.

Valencia Londoño, Paula A., Susana Pérez-Gallart Mingrone y Omar Mancera González, eds. Empoderamiento pacifista. Medellín - Granada: Sello Editorial de la Universidad de Medellín - Editorial de la Universidad de Granada, 2017.

Vattimo, Gianni. El fin de la modernidad. Nihilismo y hermenéutica en la cultura posmoderna. Barcelona: Gedisa, 1998.

Wagensberg, Jorge. Ideas acerca de la complejidad del mundo. Barcelona: Tusquets, 1985.

Weber, Max. Economía y sociedad. Esbozo de sociología comprensiva. Madrid: Fondo de Cultura Económica, 2008.

Zioga, Ioanna, Rawan Hassan y Caroline Di Bernardi Luft. "Success, but not failure feedback guides learning during neuro feedback: An ERP study". NeuroImage 200, n. ${ }^{\circ} 1$ (2019): 26-37.

\section{Cómo citar:}

Jiménez Arenas, Juan Manuel. “De la paz imperfecta a la agencia pacifista". Revista Historia de la Educación Latinoamericana. 22 No. 35 (2020): 35-64 https://doi.org/10.19053/01227238.11917

(1) $\mathbb{( \Theta \Theta}$ Esta obra está bajo una licencia Creative Commons. Reconocimiento-No Comercial-Sin Obra Derivada 2.5 Colombia. 